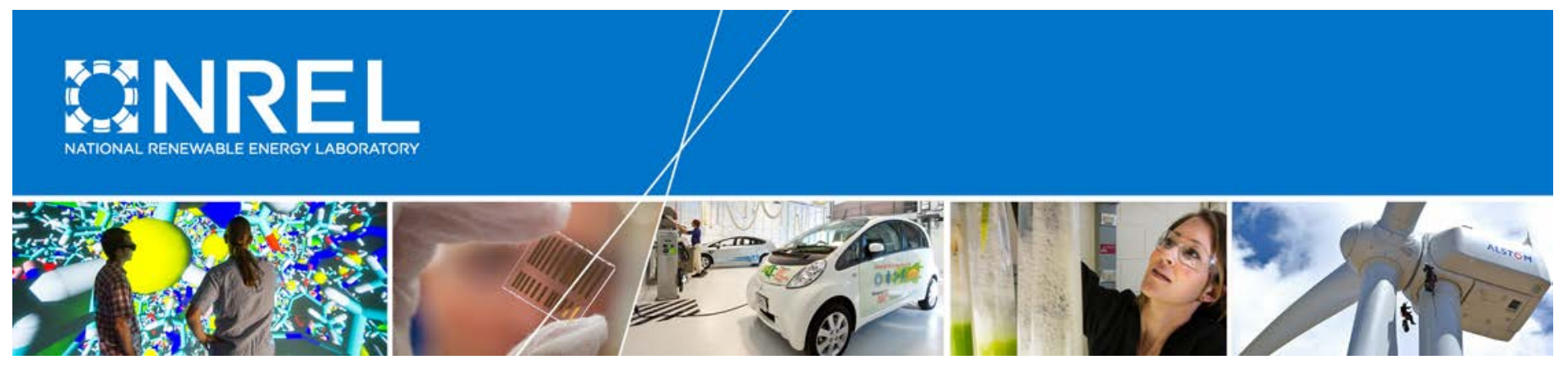

\title{
The Distributed Wind Cost Taxonomy
}

Trudy Forsyth

Wind Advisors Team

Tony Jimenez, Robert Preus, Suzanne Tegen, and lan Baring-Gould

National Renewable Energy Laboratory

NREL is a national laboratory of the U.S. Department of Energy Office of Energy Efficiency \& Renewable Energy Operated by the Alliance for Sustainable Energy, LLC

This report is available at no cost from the National Renewable Energy Laboratory (NREL) at www.nrel.gov/publications.

Technical Report

NREL/TP-5000-67992

March 2017

Contract No. DE-AC36-08G028308 


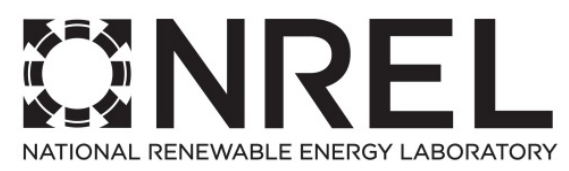

\title{
The Distributed Wind Cost Taxonomy
}

\author{
Trudy Forsyth \\ Wind Advisors Team
}

Tony Jimenez, Robert Preus, Suzanne

Tegen, and lan Baring-Gould

National Renewable Energy Laboratory

Prepared under Task No. WE152E15

NREL is a national laboratory of the U.S. Department of Energy Office of Energy Efficiency \& Renewable Energy Operated by the Alliance for Sustainable Energy, LLC

This report is available at no cost from the National Renewable Energy Laboratory (NREL) at www.nrel.gov/publications.

National Renewable Energy Laboratory 15013 Denver West Parkway

Golden, CO 80401

303-275-3000 • www.nrel.gov

\section{Technical Report}

NREL/TP-5000-67992

March 2017

Contract No. DE-AC36-08G028308 


\section{NOTICE}

This report was prepared as an account of work sponsored by an agency of the United States government. Neither the United States government nor any agency thereof, nor any of their employees, makes any warranty, express or implied, or assumes any legal liability or responsibility for the accuracy, completeness, or usefulness of any information, apparatus, product, or process disclosed, or represents that its use would not infringe privately owned rights. Reference herein to any specific commercial product, process, or service by trade name, trademark, manufacturer, or otherwise does not necessarily constitute or imply its endorsement, recommendation, or favoring by the United States government or any agency thereof. The views and opinions of authors expressed herein do not necessarily state or reflect those of the United States government or any agency thereof.

This report is available at no cost from the National Renewable Energy Laboratory (NREL) at www.nrel.gov/publications.

Available electronically at SciTech Connect http:/www.osti.gov/scitech

Available for a processing fee to U.S. Department of Energy and its contractors, in paper, from:

U.S. Department of Energy

Office of Scientific and Technical Information

P.O. Box 62

Oak Ridge, TN 37831-0062

OSTI http://www.osti.gov

Phone: 865.576.8401

Fax: 865.576.5728

Email: reports@osti.gov

Available for sale to the public, in paper, from:

U.S. Department of Commerce

National Technical Information Service

5301 Shawnee Road

Alexandria, VA 22312

NTIS http://www.ntis.gov

Phone: 800.553 .6847 or 703.605 .6000

Fax: 703.605.6900

Email: orders@ntis.gov 


\section{Acknowledgments}

The National Renewable Energy Laboratory acknowledges the U.S. Department of Energy's Wind Energy Technologies Office for supporting this work under the Office of Energy Efficiency and Renewable Energy's distributed wind research, development, and testing activities.

The authors wish to thank the following people for their help in producing this report:

- Patrick Gilman (Wind Energy Technologies Office)

- Bret Barker (in support of the Wind Energy Technologies Office).

The authors also wish to thank the following people for their preliminary cost data, which were used in validating the Distributed Wind Cost Taxonomy:

- Nils Behn, Aegis Renewable Energy

- Andrew Trapanese, BTI Energy

- Bruce Hatchett, Energy Options

- Gary and Kathryn Harcourt, Great Rock Windpower

- Jereme Kent, One Energy

- Richard Johnson, RockWind Venture Partners

- Jake West, Van Wall Energy

- Dennis Williams, Williams Power Systems

- Kevin Beers, WyCO Wind \& Solar.

The authors thank other distributed wind installers who contributed but did not wish to be acknowledged as well as Charles Newcomb, for valuable discussions regarding the organization of the taxonomy and for providing information. In addition, we thank Corrie Christol, Bethany Straw, and Al Hicks, NREL; Alice Orrell, Pacific Northwest National Laboratory; and Ruth Baranowski, High Desert Technical Communications, for their valuable assistance in compiling this report. 


\section{Acronyms and Abbreviations}

BOS

CapEx

COGS

DOE

GW

NREL

OEM

OpEx

PII

PNNL

PV

SCBS

WTSE

ZPII balance of station

capital expenditures

cost of goods sold

U.S. Department of Energy

gigawatts

National Renewable Energy Laboratory

original equipment manufacturer

operational expenditures

permitting, inspection, and interconnection

Pacific Northwest National Laboratory

photovoltaics

System Cost Breakdown Structure

wind turbine system equipment

zoning, permitting, interconnection, and incentives 


\section{Definitions}

The following words are defined with consideration about how the authors used them in the development of the taxonomy and the writing of this report.

Balance of Station Costs

CapEx

Cost of Goods Sold

Developer

Distributor

Installer

OpEx

Taxonomy
Costs to develop and commission a wind turbine project minus the wind turbine system. These costs include labor, equipment, and materials.

Capital expenditures to purchase, install, interconnect, and commission a distributed wind turbine.

Cost to manufacture a product. It includes the cost of purchased parts, materials and burdened shop labor.

Company that sells and manages the development of distributed wind turbine projects. This is more common for projects with large turbines.

Company that is an intermediary between the original wind turbine equipment manufacturer and the developer or installer.

Individual or company that installs wind turbine projects. This term is typically used for projects with small wind turbines. (Larger projects are typically sold and managed by a "developer.")

Operating expenditures include all costs to operate and maintain the wind turbine system over its lifetime.

Categorization and organization of cost items and activities needed to sell, develop, commission, and operate a distributed wind project during the entire operational life. 


\section{Executive Summary}

Wind power is one of the fastest growing sources of new electricity generation in the United States. In 2016, cumulative installed capacity was more than 82,000 megawatts (MW) (AWEA 2017); yet the distributed wind market has remained limited with cumulative installed capacity at nearly 1,000 MW during the same time period (Orrell and Foster 2016). Recent NREL modeling indicated that one way to increase competitiveness of distributed wind turbines for the U.S. and global markets is to reduce installed costs (Lantz et al. 2016).

To date, there has been no standard method or tool to analyze the installed and operational costs for distributed wind turbine systems. This report describes the development of a classification system, or taxonomy, for distributed wind turbine project costs. The taxonomy establishes a framework to help collect, sort, and compare distributed wind cost data that mirrors how the industry categorizes information. The taxonomy organizes costs so they can be aggregated from installers, developers, vendors, and other sources without losing cost details.

The U.S. Department of Energy's Wind Energy Technologies Office defines distributed wind by the project's location relative to end-use and power distribution infrastructure, rather than turbine or project size. Distributed wind includes the following:

- Wind energy systems, either off-grid or grid-connected, at homes, farms and ranches, businesses, public and industrial facilities, or other sites that offset all or a portion of the local energy consumption at or near those locations, or

- Systems connected directly to the local grid to support grid operations and local loads.

Distributed wind is differentiated from wholesale power generated at large wind farms and sent via transmission lines to substations for distribution to loads and distant end users (Orrell and Foster 2016).

Developing a peer-reviewed taxonomy is valuable to industry stakeholders because a common understanding the details of distributed wind turbine costs and balance of station costs is a first step to identifying potential high-value cost reduction opportunities. Addressing cost reduction potential can help increase distributed wind's competitiveness and propel the U.S. distributed wind industry forward. The taxonomy can also be used to perform cost comparisons between technologies and track trends for distributed wind industry costs in the future. As an initial application and piloting of the taxonomy, preliminary cost data were collected for projects of different sizes and from different regions across the contiguous United States. Following the methods described in this report, these data are placed into the established cost categories.

A combination of a general downward trend in state and federal incentive programs and funding levels, the relatively low cost of electricity (driven by low natural gas prices), and competition from other technologies, such as solar photovoltaics, has led to a market contraction (Orrell and Foster 2016). Additional work shows that without sizable cost reductions, it will be increasingly difficult for distributed wind technologies to compete in the energy market (Lantz et al. 2016). Between 2008 and 2012, the solar industry cost reductions were primarily due to photovoltaic module price decline. Since then, cost reductions have come from non-module costs - primarily 
from marketing and customer acquisition, system design, installation labor, permitting and inspection, and installer margins (Barbose et al. 2015).

To allow an assessment of cost reduction opportunities, however, it is important to first understand at a detailed level the total costs associated with the technology. The following list presents key concepts that formed the basis of our research into distributed wind costs, leading to the development of the Distributed Wind Cost Taxonomy. This taxonomy:

- Is inclusive of all project costs and can be applied to any type of distributed wind project. The taxonomy is flexible enough to capture all distributed wind turbine project costs for the full spectrum of distributed wind applications, from off-grid projects using micro wind turbines through on-grid projects using utility-scale wind turbines in distributed settings.

- Establishes a common foundation for stakeholder discussion and analysis of distributed wind system costs. The taxonomy is the first organized structure of distributed wind turbine system costs. Previous efforts did not include the balance-ofstation costs or isolate the costs and time to overcome regulatory and permitting barriers. It provides a common set of terms and categories that the industry and other stakeholders can utilize for discussions and analysis — including establishing industry-wide benchmarks — on detailed costs of distributed wind turbine systems.

- Builds on a decade of work performed by photovoltaics and utility-scale wind analysts. The taxonomy was informed by the land-based Wind System Cost Breakdown Structure (an internal National Renewable Energy Laboratory (NREL) model) and the photovoltaic system cost breakdown (Barbose et al. 2015). Both of these cost breakdowns have been useful in collecting total costs for installing utilitygrade wind and solar projects, leading to a greater understanding of cost-reduction opportunities. The Distributed Wind Cost Taxonomy utilizes this previous work to efficiently identify cost items for inclusion.

- Has been vetted with industry and validated through preliminary data collection. NREL and the Pacific Northwest National Laboratory developed the draft taxonomy and presented it to industry stakeholders on two occasions. ${ }^{1}$ Vetting with industry ensured that the taxonomy was consistent with common industry cost accounting, which minimized the time required for data collection. The preliminary data collection encompassed 30 distributed wind projects using 35 distributed wind turbines.

Figure ES-1 displays the Distributed Wind Cost Taxonomy and its structure. The three top-tier groupings are:

- Wind turbine and tower costs, also known as wind turbine system equipment

\footnotetext{
${ }^{1}$ NREL introduced the draft taxonomy at the Distributed Wind Energy Association's All States Summit in September 2015 (Sacramento, CA) and at the Small Wind Conference in June 2016 (Stevens Point, WI).
} 
- Balance-of-station costs, the labor and equipment costs for preparation and the on-site work to install a distributed wind system in a specific location ${ }^{2}$

- Operations and maintenance costs, the costs to operate and maintain the distributed wind system throughout its lifetime.

These groupings are followed by second-tier categories, such as rotor assembly, nacelle assembly, and electrical system, and by third-tier or lower-level categories not shown here.

The balance-of-station top tier includes all of the labor, equipment, and material costs for the preparatory work to identify a customer or host, seek project approval, purchase materials, and build the on-site infrastructure, such as foundations and electrical infrastructure, and install the turbine(s) at a specific location. All of the costs for wind system equipment and balance of station are referred to as capital expenditures (CapEx). In other words, CapEx covers all of the costs for installing a wind system. The operation and maintenance (operational expenditures or OpEx) top tier includes labor, equipment, and materials associated with operational wind turbine(s). This category's lower levels also include replacement parts. Figure ES-1 shows the top tiers in bold, the second tiers underneath the bold top tiers, and the third tiers in bulleted lists.

A recent NREL analysis, Assessing the Future of Distributed Wind: Opportunities for Behindthe-Meter Projects (Lantz et al. 2016), shows that reducing installed costs of distributed wind systems is one way to increase competitiveness, though cost reductions alone are not sufficient to ensure widespread adoption of distributed wind systems. Along with access to lower-cost capital and increased public awareness, more cost-effective installed, distributed wind systems could result in wider market adoption of distributed wind turbines and an expansion of United States manufacturing. The development of an accepted Distributed Wind Cost Taxonomy informs industry stakeholders and facilitates creation of an industry-wide project cost baseline that can be used for future analyses and to establish areas for potential cost reduction.

\footnotetext{
2 The terms "balance of system" and "balance of station" are used in other taxonomies or cost breakdown structures. These terms are interchangeable; for this report, we use "balance of station," which is more popular in the distributed wind literature.
} 
Wind Turbine System Equipment (CapEx)

Wind Turbine

- Rotor Assembly

- Nacelle Assembly

- Electrical System

- Manufacturer Overhead and Profit

- Warranty
Tower

- Tower Hardware and Miscellaneous

- Manufacturer Overhead and Profit

\section{Balance of Station (CapEx)}

Customer Acquisition and Qualification

- Marketing and Advertising

- $\quad$ Site Assessment

- Wind Resource Assessment

Zoning, Permitting, Interconnection, Incentives (ZPII)

- Zoning

- Permitting

- Interconnection

- Incentives Processing

Engineering and Design

- Engineering Studies

- Inspections and Testing

Transportation and Logistics

Foundation

- Labor

- Equipment

- Materials
Electrical Infrastructure

- Labor

- Equipment

- Materials

Installation

- $\quad$ Site Preparation and Cleanup

- Turbine and Tower Assembly and Erection

- Commissioning

- Other Installation-Related Costs

Taxes

- Sales Tax

- Import Tax

Other Project Costs

Overhead and Profit

Financing and Transaction Costs

\section{Operations and Maintenance $(\mathrm{OpEx})$}

Operations

Maintenance

- Scheduled maintenance

- Unscheduled

\section{Figure ES-1. Distributed Wind Cost Taxonomy top three tiers}




\section{Table of Contents}

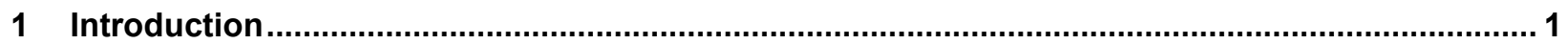

1.1 Distributed Wind Opportunities and Challenges...................................................... 1

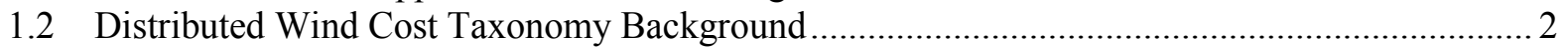

1.3 Why the Distributed Wind Cost Taxonomy Is Important ...................................................... 3

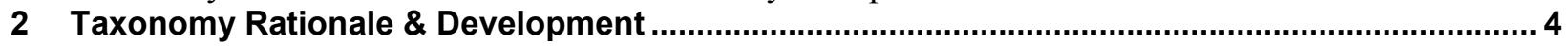

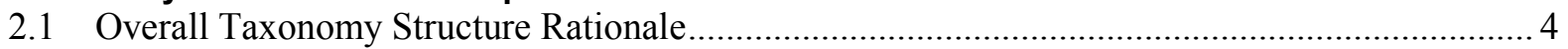

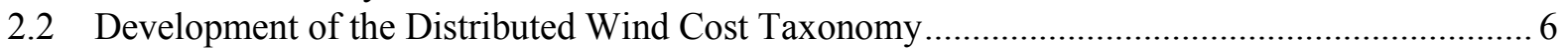

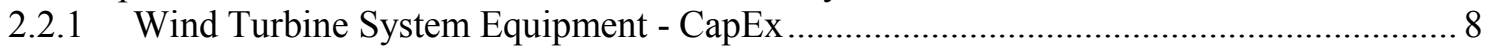

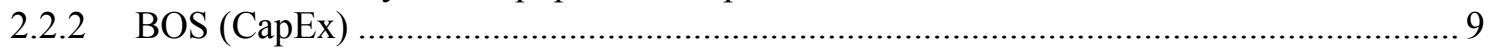

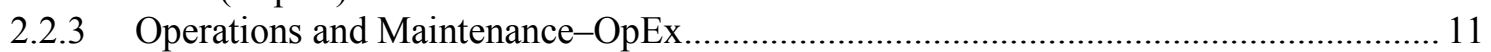

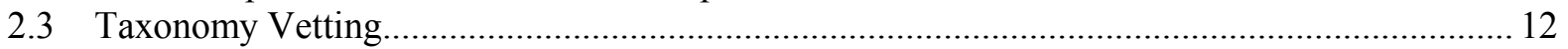

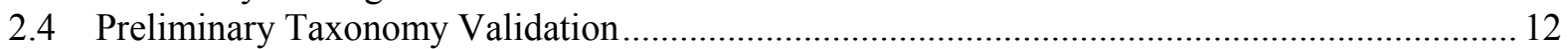

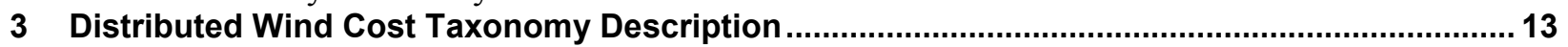

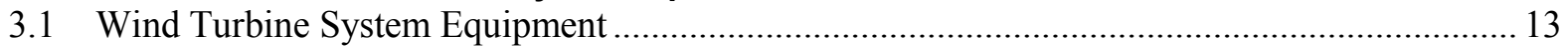

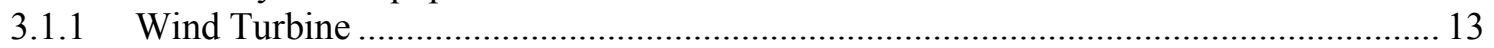

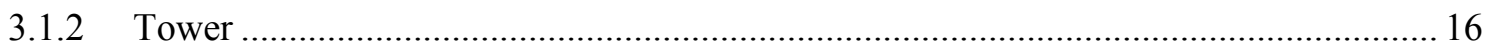

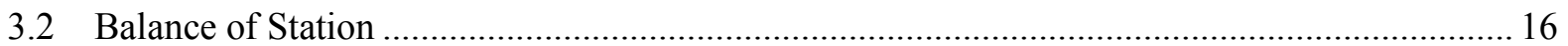

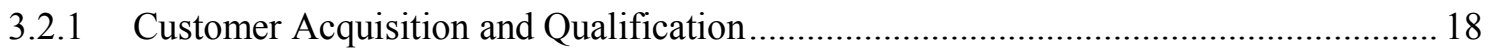

3.2.2 Zoning, Permitting, Interconnection, and Incentive Processing.................................... 19

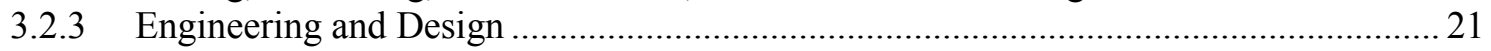

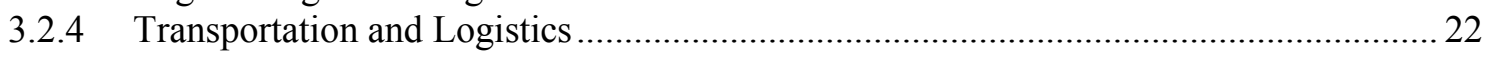

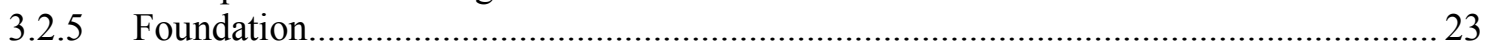

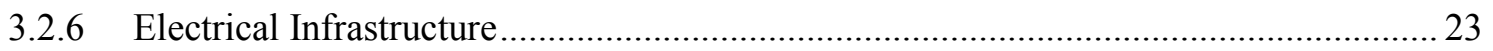

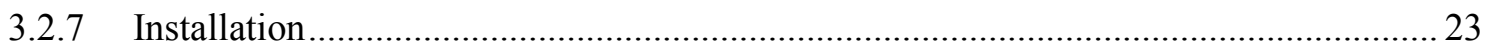

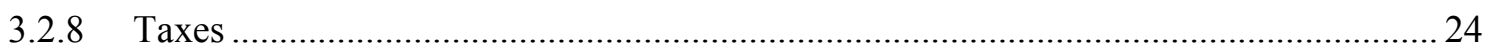

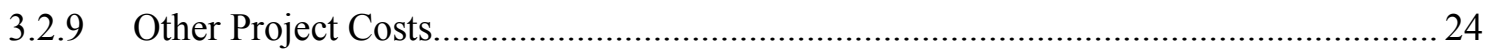

3.2.10 Overhead and Profit .................................................................................... 25

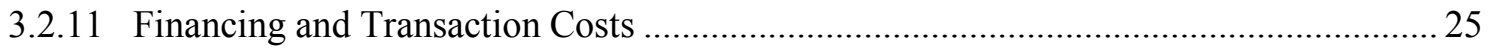

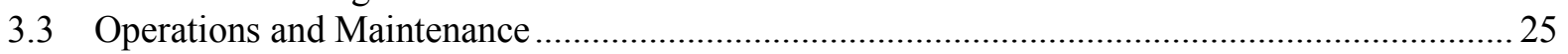

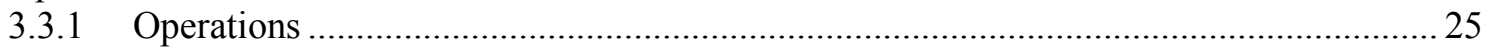

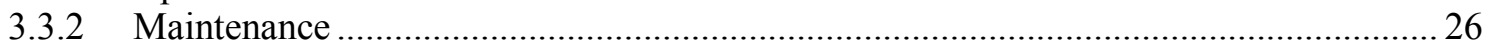

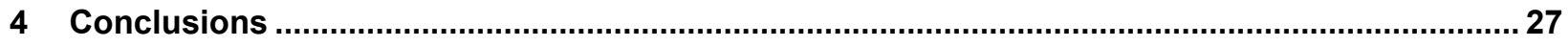

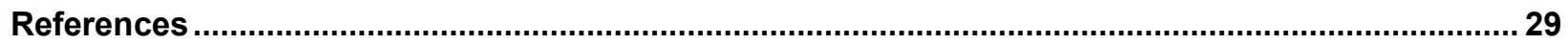




\section{List of Figures}

Figure ES-1. Distributed Wind Cost Taxonomy top three tiers............................................................. ix

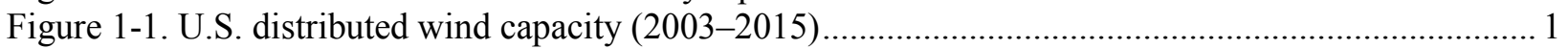

Figure 1-2. High-level cost similarities of land-based wind SCBS, Distributed Wind Cost Taxonomy, and

PV taxonomy ........................................................................................................ 3

Figure 2-1. Distributed Wind Cost Taxonomy with the first and second tiers labeled............................... 7

Figure 2-2. Land-based wind SCBS, Distributed Wind Cost Taxonomy, and PV taxonomy details........... 8

Figure 2-3. First-, second-, and third-tier categories under "Wind Turbine System Equipment" ............... 9

Figure 2-4. Distributed wind technology size ranges. Source: NREL (Lantz et al. 2016)........................ 11

Figure 3-1. Details of wind turbine system equipment categories (CapEx) ........................................... 14

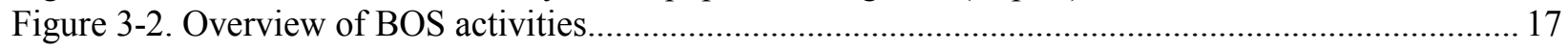

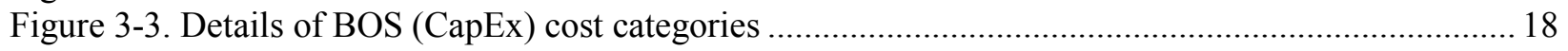

Figure 3-4. Break-out of the BOS (CapEx) categories from "Transportation and Logistics" to "Taxes"..22

Figure 3-5. Details of Operations and Maintenance cost categories........................................................26 


\section{Introduction}

This report describes the development of a classification system, or taxonomy, for distributed wind turbine installation and operation costs. Previously, such a system did not exist; so creating one allows for consistent categories and naming to evaluate distributed wind costs and a structure to build a reliable data set for distributed wind cost benchmarking.

\subsection{Distributed Wind Opportunities and Challenges}

The United States set a new record in 2016 for annual renewable energy capacity additions, adding 22 gigawatts (GW) of renewable generating capacity (Bloomberg 2017). Even though the amount of distributed generation has doubled, the domestic distributed wind industry has been experiencing a decline in capacity additions and investment since its high point in 2012. The decline in the U.S. distributed wind market can be attributed to significant decreases in state and federal incentives and programs, low average electricity and natural gas costs, and competition from solar photovoltaics (PV). As Figure 1-1 shows, this decline began in 2013, according to the U.S. Department of Energy's (DOE's) 2015 Distributed Wind Market Report (Orrell and Foster 2016).

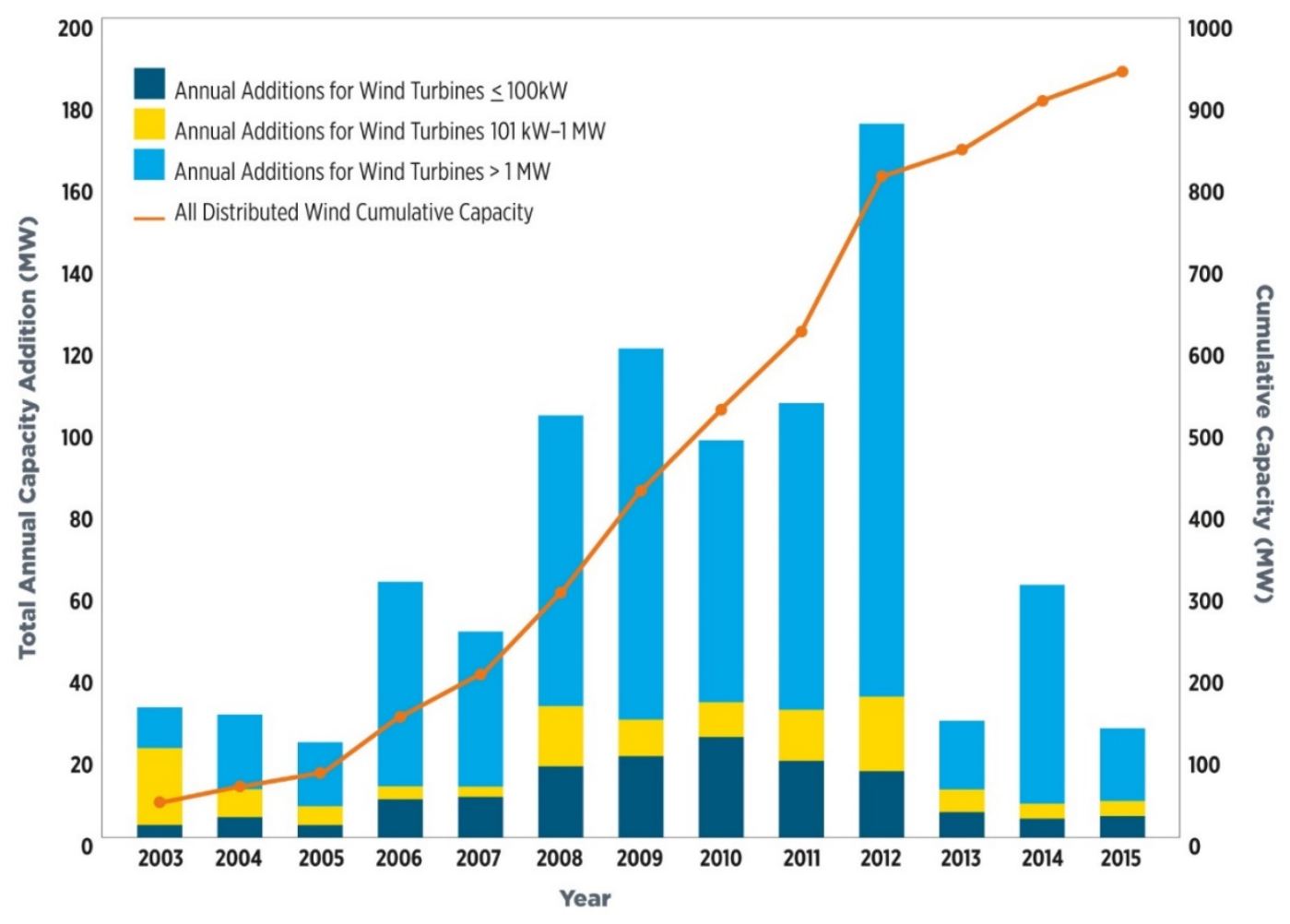

Figure 1-1. U.S. distributed wind capacity (2003-2015)

PV technology has experienced a dramatic price decline, and to compete in the distributed renewables market, distributed wind companies must find strategies to be cost-competitive with both relevant retail electricity rates and PV.

A recent National Renewable Energy Laboratory (NREL) analysis, Assessing the Future of Distributed Wind: Opportunities for Behind-the-Meter Projects (Lantz et al. 2016), shows that 
reducing installed costs of distributed wind systems is one way to increase competitiveness, although cost reductions alone are not sufficient to ensure widespread adoption of distributed wind systems. Understanding the detailed costs for distributed wind turbines and systems is a necessary starting point to identifying potential cost reduction opportunities that can help propel the U.S. distributed wind industry forward. This taxonomy report establishes a standard structure for collecting distributed wind cost data that can be used to analyze cost reduction opportunities and compare the costs of different projects and technologies.

\subsection{Distributed Wind Cost Taxonomy Background}

To quantify the factors that determine the installed cost of a distributed wind system, a framework is needed that allows data from installers, developers, and other sources to be combined without losing cost details. NREL worked with DOE, the Pacific Northwest National Laboratory (PNNL), and the distributed wind industry to develop the new taxonomy to serve these needs. Other cost breakdowns informed the Distributed Wind Cost Taxonomy: DOE's Solar Energy Technologies Office created the PV taxonomy (Barbose et al. 2015), and NREL developed the utility-scale, land-based Wind System Cost Breakdown Structure (SCBS) (Moné et al. 2015). The similarities and differences between these other taxonomies are explained in detail in this report. In general, the cost components for utility-scale wind detailed in the SCBS share common technology hardware with distributed wind turbines, but the SCBS balance of station (BOS) is for a wind farm wherein multiple turbines are co-located and therefore includes a number of cost categories that are not applicable to distributed wind.

Distributed wind projects are similar to distributed PV projects in a number of ways, so they have many common cost items. The PV taxonomy's BOS categorization therefore serves as the baseline for the Distributed Wind Cost Taxonomy BOS categorization.

As shown in Figure 1-2, the top-tier Distributed Wind Cost Taxonomy broadly follows the wind SCBS except for BOS. Like the wind SCBS, and in contrast to the PV taxonomy, the Distributed Wind Cost Taxonomy includes a cost category for operational expenditures (OpEx). For distributed wind, an understanding of the operation and maintenance expenses is important because maintenance is a significant levelized cost of energy driver. 


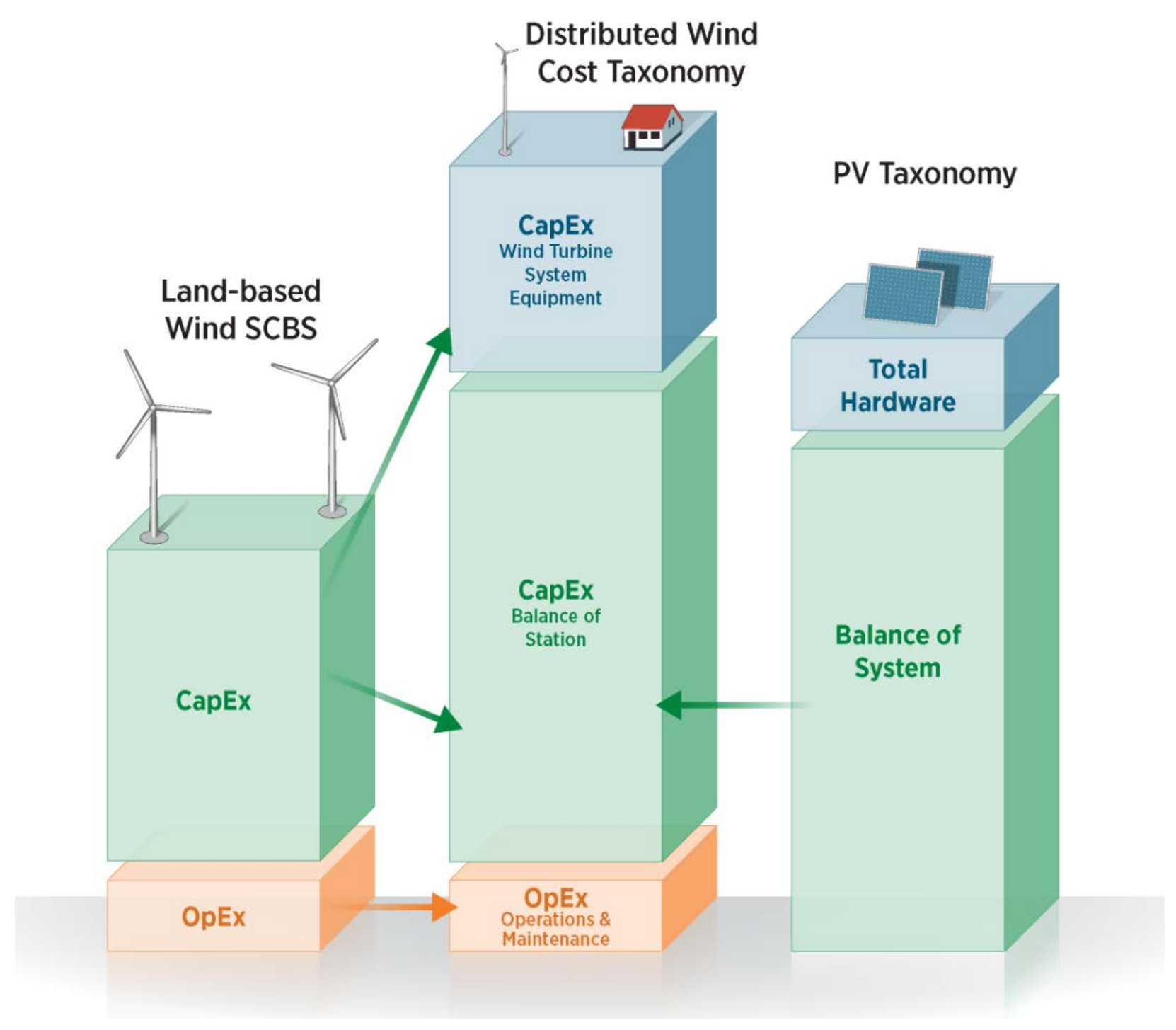

Figure 1-2. High-level cost similarities of land-based wind SCBS, Distributed Wind Cost Taxonomy, and PV taxonomy

The Distributed Wind Cost Taxonomy closely follows the PV taxonomy categorization of BOS costs, given similarities in acquiring customers, seeking regulatory and utility interconnection approval, and installing projects in individual or small clusters.

\subsection{Why the Distributed Wind Cost Taxonomy Is Important}

The taxonomy facilitates collection of standardized data that can be used to analyze and track costs, technology changes, and other trends across distributed wind turbine system sizes, regions, and business models. This taxonomy covers costs related to the turbine equipment, related to BOS costs necessary to put the distributed wind project into operation, and operating and maintaining the project over its operating lifetime. 
This taxonomy is flexible enough to capture costs from any type of distributed wind turbine project - grid-connected or off-grid - from a "community wind" project of several utility-scale wind turbines interconnected on a local distribution system, to one or more mid-size turbines installed behind the meter to serve a factory's onsite load, to a small turbine interconnected to the utility grid, to a single micro turbine as part of a hybrid system serving an off-grid application. Further, this taxonomy sets the categorization and syntax for wider stakeholder discussion on cost reduction opportunities, which is critical to improving the competitiveness of U.S. original equipment manufacturers (OEMs) and deploying more United States distributed wind projects.

\section{Taxonomy Rationale \& Development}

A well-structured taxonomy helps identify the major distributed wind project cost drivers to inform future cost reduction efforts.

\subsection{Overall Taxonomy Structure Rationale}

This section explains the rationale we used to develop the Distributed Wind Cost Taxonomy. The taxonomy should be:

- Comprehensive enough to cover all wind turbine costs. The taxonomy should be comprehensive, accounting for all costs for the purchase of the turbine equipment, installation and interconnection of that equipment, and maintenance of the wind turbine system over its operating lifetime. The taxonomy should capture all capital and operational expenditures, including business overhead and profit.

- Able to capture all common cost categories without being unwieldy. To be useful, the taxonomy should have a category into which every cost item can be placed, but it should also not be too detailed. For cost items that were not commonly used (e.g., cyber security hardware, waste disposal fees), an "other" category was created to capture these costs.

- Focused on the costs incurred to implement a DW project. This taxonomy includes categories for costs that would be directly incurred by a project developer, owner or operator in the development, installation and operation of a locally deployed distributed wind project. Costs that are not borne by the developer, owner, or operator as a part of implementing or operating the distributed wind project (such as any incremental costs incurred by system operators as a result) are not included in the Distributed Wind Cost Taxonomy.

- Applicable to a wide range of distributed wind turbine and project sizes. Distributed wind projects involve turbines with a rated power ranging from a few hundred watts to more than 3 megawatts. Corresponding installed costs for grid-connected wind turbines range from roughly $\$ 10,000$ to several million dollars. Installation processes that are suitable for installation of a 2.1-kilowatt $(\mathrm{kW})$ rated turbine would be inadequate for the installation of a 2-megawatt turbine (e.g., additional project management). Accounting for the costs incurred by the distributed wind projects involving larger turbines requires a more detailed taxonomy than is needed for projects using smaller turbines. Line items such as "Operations," "Financing and Transaction Costs," and "Other Project Costs" were included to accommodate larger wind turbine projects. 
- Based on workflow from installers and developers. In general, the taxonomy is organized in the same way that installers and developers organize their costs, which should simplify its use and provide expanded applicability.

- Informed by existing related taxonomies. The Distributed Wind Cost Taxonomy greatly benefited from pre-existing breakdowns and benchmarks such as the land-based wind SCBS (Moné et al. 2015) and the solar PV system soft cost benchmark reports (Friedman et al. 2013; Barbose et al. 2015). Figure 2-1 shows which sections of the new taxonomy were based on the established wind SCBS and which originated from the PV cost breakdown.

The following items informed the structure of the Distributed Wind Cost Taxonomy (see Figure 1-2):

- Wind SCBS. NREL researchers developed this detailed and comprehensive taxonomy as part of an effort to standardize renewable energy taxonomies across different technologies. Focused on utility-scale projects, the wind SCBS is more detailed (containing six tiers with more than 250 categories) than is needed to capture cost categories for distributed wind projects, which has three tiers (top-tier, second-tier, and third-tier) and 30 third-tier categories within the taxonomy. For two of the three top-tier items, the Distributed Wind Cost Taxonomy follows a modified version of the wind SCBS and includes wind turbine system equipment and OpEx.

- PV benchmark reports. DOE's SunShot initiative created PV benchmarks as part of its component- and system-level cost methodology (Chung et al. 2015). The SunShot initiative used PV cost breakdowns to better understand PV system costs and to benchmark changes in PV prices as a function of different ownership models, specifically third-party ownership. Due to the similarities in markets, policies, and regulatory practices between distributed PV and distributed wind, the PV benchmark work was relevant to the distributed wind taxonomy. It identified cost categories such as customer acquisition, permitting, and interconnection. It also identified the overhead and profit cost categories and provides a methodology for estimating these costs. In this report, we will refer to the PV benchmarking effort and PV cost breakdown as the "PV taxonomy."

- Unpublished midsize turbine cost study. As part of a 2012-2013 effort to better understand the installed costs of midsize wind turbine projects, NREL researchers collected installed cost data for 14 distributed wind projects using turbines with a nominal rated power of 100 to $900 \mathrm{~kW}$. The researchers created a cost breakdown structure to facilitate data collection and analysis. One lesson learned from this effort is that project management, construction management, and company overhead costs were not requested and thus were not disaggregated; however, they were allocated across the other cost categories.

- American Recovery and Reinvestment Act, Section 1603 data. NREL researchers examined cost breakdowns from more than 100 distributed wind projects that were submitted as part of 1603 program applications (U.S. Department of the Treasury 2016). The program did not mandate a specific format for these cost breakdowns; thus, the cost breakdowns from the 1603 program varied significantly in structure and in the level of detail provided. However, in aggregate, by tracking the frequency with which various 
cost items are listed, these cost breakdowns provide an overview of the most common distributed wind cost items.

In addition, the aggregate cost breakdowns show how project developers and installers categorize distributed wind project costs. In a sense, the 1603 data provide a poll of cost breakdown accounting approaches. The 1603 cost breakdowns provide the most detail on BOS-type costs (e.g., installation costs, permitting, and consultants). The cost breakdowns used in the 1603 program influenced the Distributed Wind Cost Taxonomy structure and the lower-tier categories that are included. Examples of this influence are the specific permits included in the Distributed Wind Cost Taxonomy and the categories included beneath installation.

\subsection{Development of the Distributed Wind Cost Taxonomy}

At the highest level, the Distributed Wind Cost Taxonomy is divided into three top-tier items shown in Figure 2-1. Figure 2-1 labels the first and second tiers in the taxonomy. Tier 2 item costs such as "Installation" are further divided into third tiers, such as "Site Preparation and Clean-up" and "Commissioning" as shown in Chapter 3. These can be broken down further into fourth tiers, depending on the cost analysis needed. The graphic uses abbreviations for two categories: Customer Acquisition and Qualification (Customer A\&Q) and "Zoning, Permitting, Interconnection and Incentives" (ZPII).

- Wind Turbine System Equipment (CapEx)

- $\operatorname{BOS}(\mathrm{CapEx})$

- Operations and Maintenance (OpEx). 


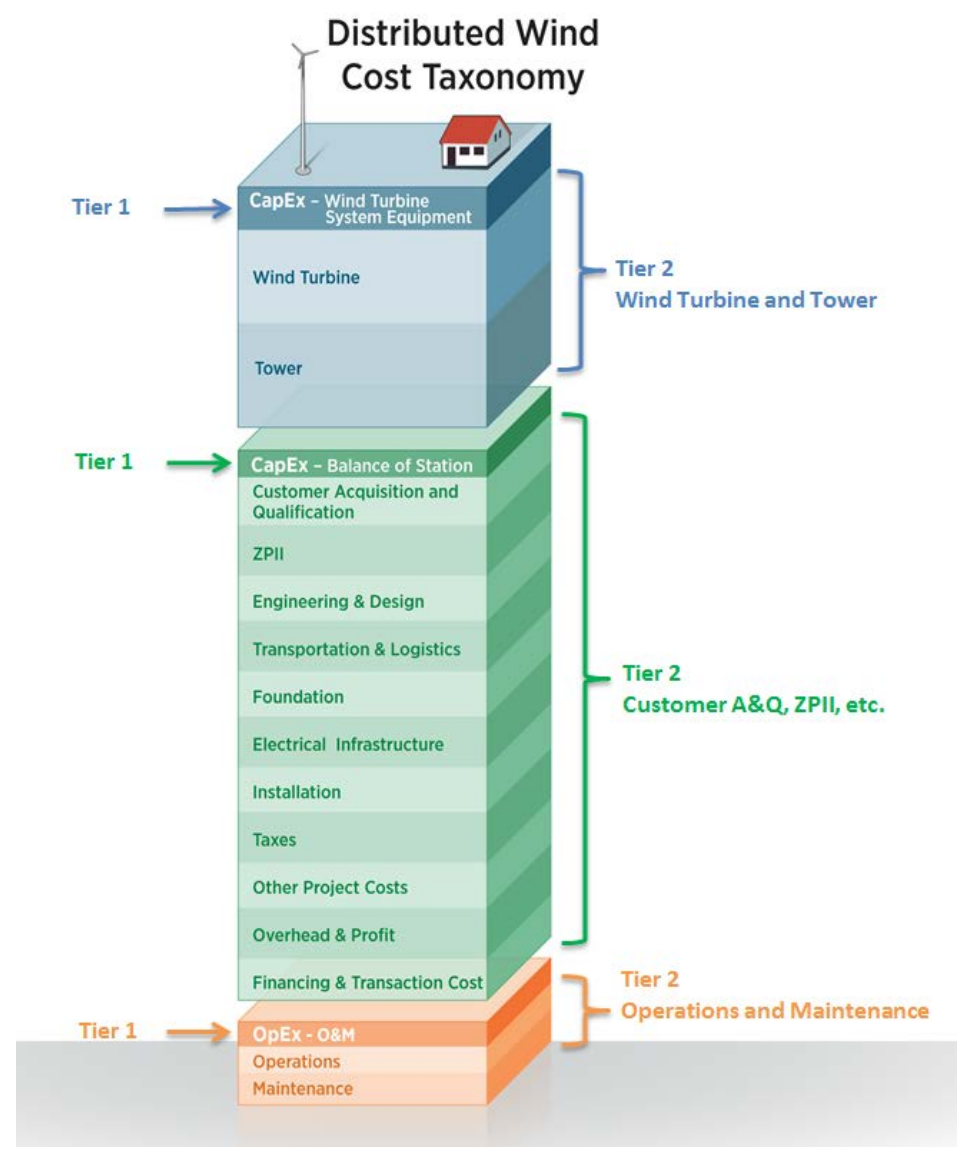

Figure 2-1. Distributed Wind Cost Taxonomy with the first and second tiers labeled

The wind SCBS has only two top-tier items: CapEx and OpEx. The PV taxonomy focuses only on capital costs in two top-tier items: hardware and balance of system. It should be noted that although the Distributed Wind Cost Taxonomy is logically separated into three top tiers, the lower-level tiers can be combined in different ways to suit a specific need, such as comparing permitting costs across multiple technologies. Figure 2-2 shows a side-by-side comparison of the first and second tiers of the Wind SCBS, Distributed Wind Cost Taxonomy, and PV taxonomy. 


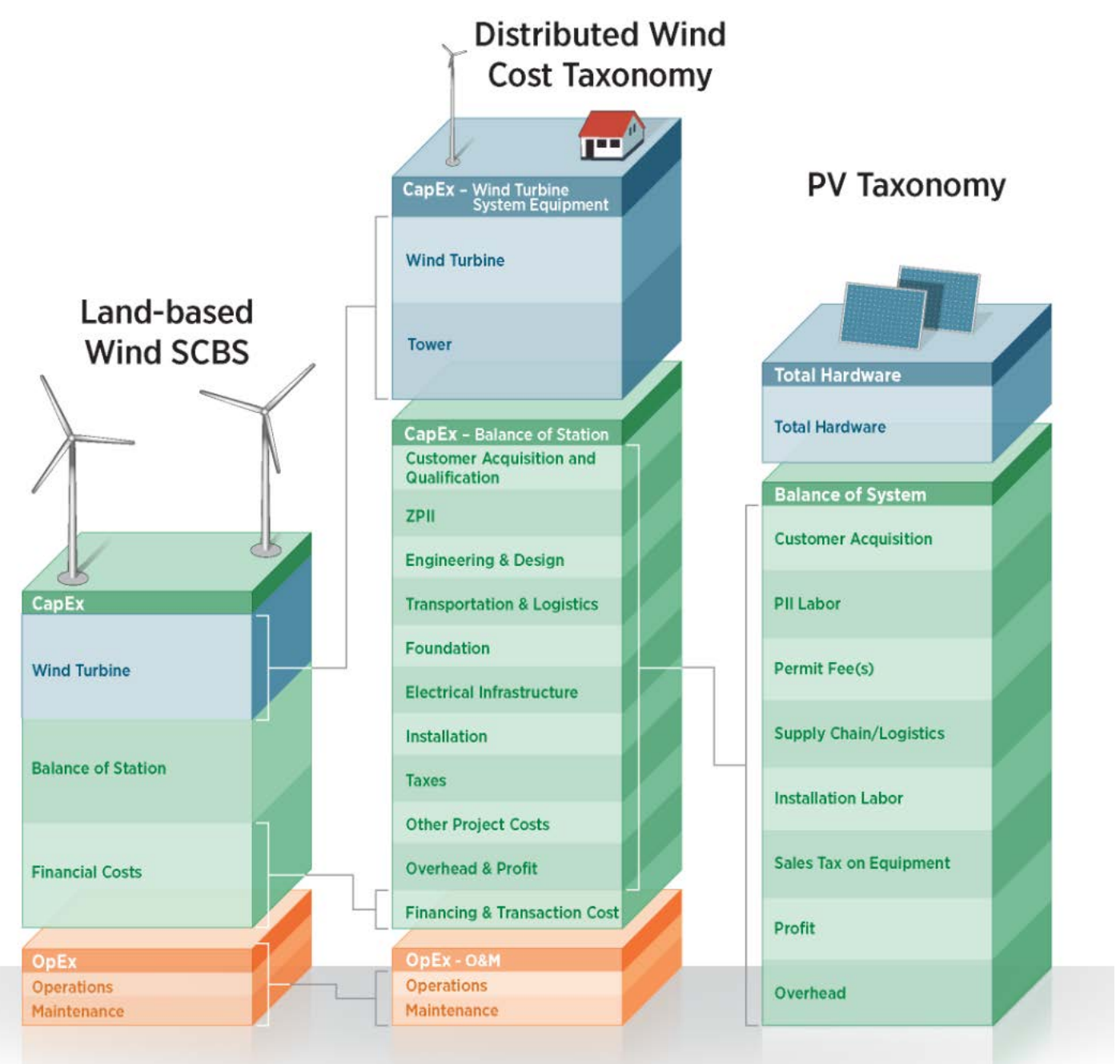

Figure 2-2. Land-based wind SCBS, Distributed Wind Cost Taxonomy, and PV taxonomy details

\subsubsection{Wind Turbine System Equipment - CapEx}

The wind SCBS was used as a starting point for the organization of the wind turbine system equipment portion of the Distributed Wind Cost Taxonomy, given similar technology. This first tier is called Wind Turbine System Equipment. Below, we explain the second tiers (e.g., "Wind Turbine") and third tiers (e.g., "Rotor Assembly").

\subsubsection{Wind Turbine}

Under "Wind Turbine," the wind SCBS has three categories: rotor module, nacelle module, and tower module. The Distributed Wind Cost Taxonomy includes six third-tier categories under wind turbine system equipment: rotor assembly, nacelle assembly, electrical system, monitoring equipment, warranty, and manufacturer's overhead and profit. Figure 2-3 shows all six third-tier categories under "Wind Turbine." 


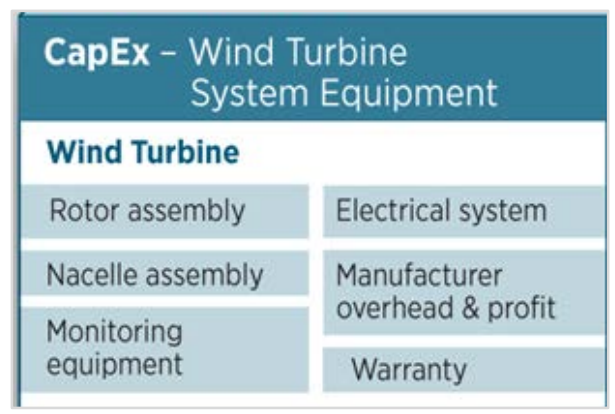

Figure 2-3. First-, second-, and third-tier categories under "Wind Turbine System Equipment"

\subsubsection{Tower}

Starting with the wind SCBS, we moved "Tower" to the same tier as the turbine, which makes it another second-tier item under Wind Turbine System Equipment (CapEx). See Figure 2-2 for "Turbine" and "Tower" second tier categories. We made this decision because towers may be procured separately from the rest of the wind turbine system equipment and having an additional item accommodates smaller wind turbine projects that can utilize a variety of tower types and heights.

\subsubsection{BOS (CapEx)}

The BOS is structured after the PV taxonomy. The first tier includes all the data categories found in the PV taxonomy outside the total hardware. In the PV taxonomy, cost categories are first organized by type (labor, equipment, and/or materials) and then different work items. In the Distributed Wind Cost Taxonomy, costs are collected primarily by type of work and then by breakdown into labor, equipment, and materials. The second-tier categories under BOS are listed in the order in which they occur in the project development cycle and are defined below and pictured in Figure 2-2 (in green). For each second-tier category, we describe deviations from the PV taxonomy below.

\subsubsection{Customer Acquisition and Qualification}

For distributed wind turbine projects, the process of identifying a customer also requires qualification of the customer, the wind resource, and the site. Because of the sensitivities of the wind resource, qualifying a prospective distributed wind project is more complicated and requires more effort than acquiring a customer for a solar PV project.

\subsubsection{Zoning, Permitting, Interconnection, and Incentives Processing}

The PV taxonomy accounts for permitting, inspection, interconnection, and incentive costs, which are further broken down into labor and fees. The Distributed Wind Cost Taxonomy expands this category to include zoning, a prevalent distributed wind market barrier. Inspection is part of the regulatory and utility approval process and is included as part of permitting.

\subsubsection{Engineering and Design}

Engineering and design efforts vary by type of wind equipment used, project site, and utility interconnection requirements. Trying to understand the details of these engineering costs becomes important in comparing and capturing total installed wind turbine costs. Engineering and design covers engineering costs outside of the permitting approval costs. Different 
jurisdictions will require different permits, and engineering services may be needed to obtain specific permitting approval; those costs are categorized in permitting.

\subsubsection{Transportation and Logistics}

In the PV taxonomy, supply chain accounts for intermediary markups and transportation costs. Historically distributors served as intermediaries between the OEM and installer/developer in the U.S. market. Presently, wind projects do not have distributors, so the supply chain cost was excluded as a category in the wind taxonomy. However, there can be significant transportation costs for large turbine projects, so capturing transportation costs in this category is important. The title of this category in the taxonomy is "Transportation and Logistics."

\subsubsection{Foundation}

Foundation installation precedes the rest of the installation effort and is linked to specific types of towers and soil types. Based on preliminary data gathered, some installers and developers install the foundation and others subcontract the work to lower-level contractors. These contracts typically have a foundation price, which may include breakout of labor, equipment, and materials.

\subsubsection{Electrical Infrastructure}

Based on preliminary data, we found that some distributed wind projects subcontracted electrical infrastructure design services. For those projects, the electrical infrastructure price may not include a breakout into labor, equipment, and material costs. If direct installer labor is used for the electrical work, the costs may be broken out into labor, equipment, and materials.

\subsubsection{Installation}

The physical installation of the turbine comprises the following third-tier categories: site preparation, turbine and tower assembly and erection, turbine commissioning, and other installation costs as shown in Figure 3-3. This particular breakout originates from a review of more than 100 distributed wind projects in the Section 1603 data, which highlighted how installation costs were organized.

\subsubsection{Taxes}

This category in the Distributed Wind Cost Taxonomy is the same as the one for the PV taxonomy and includes sales taxes and import taxes.

\subsubsection{Other Project Costs}

This category was added to capture BOS costs that do not fit elsewhere in the taxonomy under the BOS tier. It includes costs that are so infrequently encountered, such as extensive cyber security upgrades, that they do not merit a separate titled category in the taxonomy.

Decommissioning bonds, funds set aside to allow for the decommissioning of the project after useful life, are another example of an additional cost.

\subsubsection{Overhead and Profit}

The Distributed Wind Cost Taxonomy combines the separate PV taxonomy categories of "Overhead" and "Profit" into one category to be more inclusive of the different business accounting methods for overhead and profit costs. 


\subsubsection{Financing and Transaction Costs}

For financial costs, we looked to the wind SCBS and the PV taxonomy. Financial costs in the wind SCBS are on the same tier as BOS. Utility-scale wind projects have higher costs, utilizing complex financing structures in which transaction costs (e.g., business, legal) and other aspects of project financing are key project cost drivers. In contrast, most distributed wind projects, especially those involving residential and commercial-size turbines (see below for turbine sizes), use simple business structures (typically an end-user cash purchase or a lease with the hosting residence or facility). Figure 2-4 shows the distributed wind technology size classifications. To reflect this simplified financial structure, in the Distributed Wind Cost Taxonomy the category "Financing Costs" is moved down a tier and placed within BOS. In addition, it is relabeled "Financing and Transaction Costs" because it includes all financing and transaction costs.

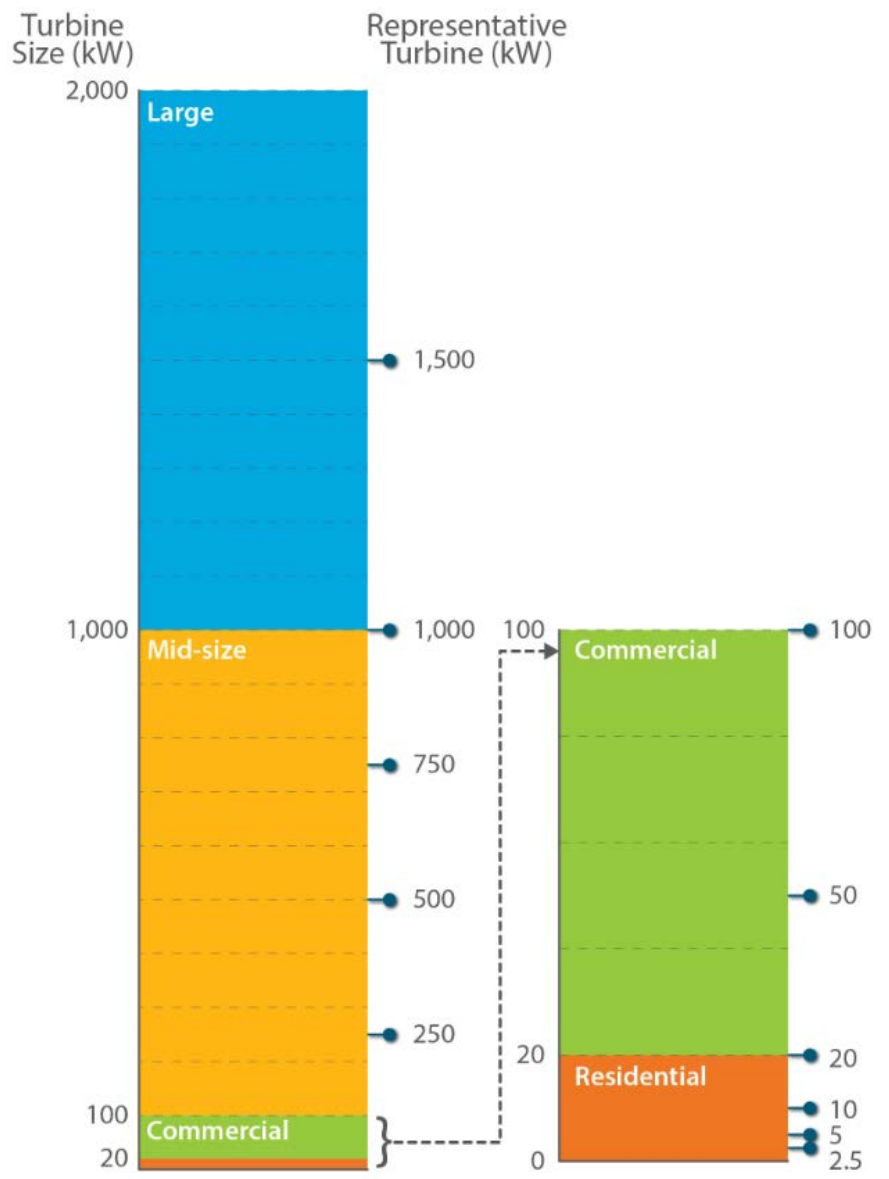

Figure 2-4. Distributed wind technology size ranges. Source: NREL (Lantz et al. 2016)

\subsubsection{Operations and Maintenance-OpEx}

For the Distributed Wind Cost Taxonomy, the wind SCBS "Operational Expenditures" were relabeled to the more commonly used (in wind power reporting) "Operations and Maintenance." Under this top-tier category, both taxonomies contain two second-tier categories, "Operations" and "Maintenance." In the wind SCBS, "Operations" includes categories such as environmental monitoring, land leases, Federal Energy Regulatory Commission fees, and weather forecasting, which are almost never applicable to distributed wind installations. 
The wind SCBS has three second-tier categories under "Maintenance": "Scheduled Maintenance," "Unscheduled Maintenance," and "Long-Term Service Agreement." The Distributed Wind Cost Taxonomy retains the first two categories and discards the last one because a long-term service agreement is a contractual means for acquiring maintenance services typically used in the distributed wind market space. If a decommissioning fund is used to cover potential decommissioning costs, then annual payments can be classified under long-term service.

Replacement parts that are installed during scheduled maintenance due to wear or expected service life limits are part of the Scheduled Maintenance cost. The same part installed as a result of an unexpected and sudden failure is part of the Unscheduled Maintenance cost.

\subsection{Taxonomy Vetting}

An initial version of the Distributed Wind Cost Taxonomy was created in September 2015 and presented at a meeting held in conjunction with the Distributed Wind Energy Association conference that same month. The meeting attendees agreed with the overall taxonomy structure. Several key issues were discussed during the sessions, including the following:

- One key topic was where to place engineering tasks that are conducted only to meet a permitting requirement. Examples of these tasks include a geotechnical analysis or procuring a wet stamp on a tower design. These activities could arguably either go under "Engineering and Design" or "ZPII," given that they are often conducted as part of the permitting process. It was decided to place the costs for these activities within "ZPII" to better characterize the aggregate regulatory burden.

- An additional discussion point was how and where to account for the costs of identifying a customer or host and ensuring that the customer, the site, and the wind resource qualify as a viable project. There can be substantial engineering/technical effort to evaluate project viability. These costs and this entire activity are accounted for in "Customer Acquisition and Qualification."

- Warehousing and storage costs for small wind installers were also discussed. Meeting attendees noted that if wind turbine systems or towers are purchased in bulk, there may be an intermediary warehousing activity before the equipment is transported to the end user's site. These costs are part of "Transportation and Logistics," a second tier under BOS.

A revised taxonomy was presented to an audience of installers and manufacturers at the Small Wind Conference in June 2016. Again, the meeting attendees agreed with the taxonomy structure and understood its purpose.

\subsection{Preliminary Taxonomy Validation}

To determine whether the taxonomy would be useful for data collection, we gathered preliminary data from 10 installers and developers in April through June 2016. These data included general company information, metadata, and empirical cost data for 30 projects using 35 wind turbines with a rated power ranging from $2.1 \mathrm{~kW}$ to 1.7 megawatts. 
As part of the taxonomy validation, requests for project cost data followed by interviews with installers and developers helped to elucidate business and project cost details. In general, the installers and developers followed the cost organization of the taxonomy with ease, demonstrating that the turbine cost categories were relevant. Through these interviews, we learned that different businesses categorize their company costs differently. An example is that installers and developers capture their margin and profit in different ways. To help ensure that costs can be compared across projects, technologies, and different development types; cost information on overhead, margins, and profit is included in the second-tier category, "Overhead and Profit."

\section{Distributed Wind Cost Taxonomy Description}

This section of the report describes the taxonomy organization and tiers in detail. The taxonomy is divided into three categories: "Wind Turbine System Equipment," "BOS," and "Operations and Maintenance." The wind turbine system equipment and BOS are commonly referred to as CapEx, which includes all expenses associated with developing a project to the point of beginning operation. Operations and maintenance is commonly referred to as OpEx (for operational expenditures). This covers all expenses incurred for the operation of the wind project during its operational life.

\subsection{Wind Turbine System Equipment}

Wind Turbine System Equipment under CapEx is a top tier, shown in Figure 3-1, and is divided into two second-tier categories: "Wind Turbine" and "Tower." Each of the second-tier categories has lower or third-tier cost categories as shown in Figure 3-1.

\subsubsection{Wind Turbine}

The wind turbine is typically sold as a single item provided by an OEM, with or without a tower. Because of independent sourcing of towers, the tower has been identified as a separate secondtier item. Costs for the wind turbine equipment are divided into "Rotor Assembly," "Nacelle Assembly," "Monitoring Equipment," and "Electrical System"-all of which will have materials, parts, and manufacturing labor costs. Together these costs are typically referred to as the "cost of goods sold" (COGS). The difference between COGS and the selling price is covered in the other two second-tier items: "Warranty" and "Overhead and Profit." Although overhead and profit data are often difficult to obtain, the taxonomy provides a category for the portion of the costs included as part of a company's overhead and profit. Warranty costs can be included with overhead, in a warranty reserve that is part of the COGS, or reported separately. The taxonomy considers warranty separately because of this variation in standard accounting and because it is especially critical for distributed wind turbine companies. The wind turbine secondtier category is made up of the third-tier cost categories listed in this section. 


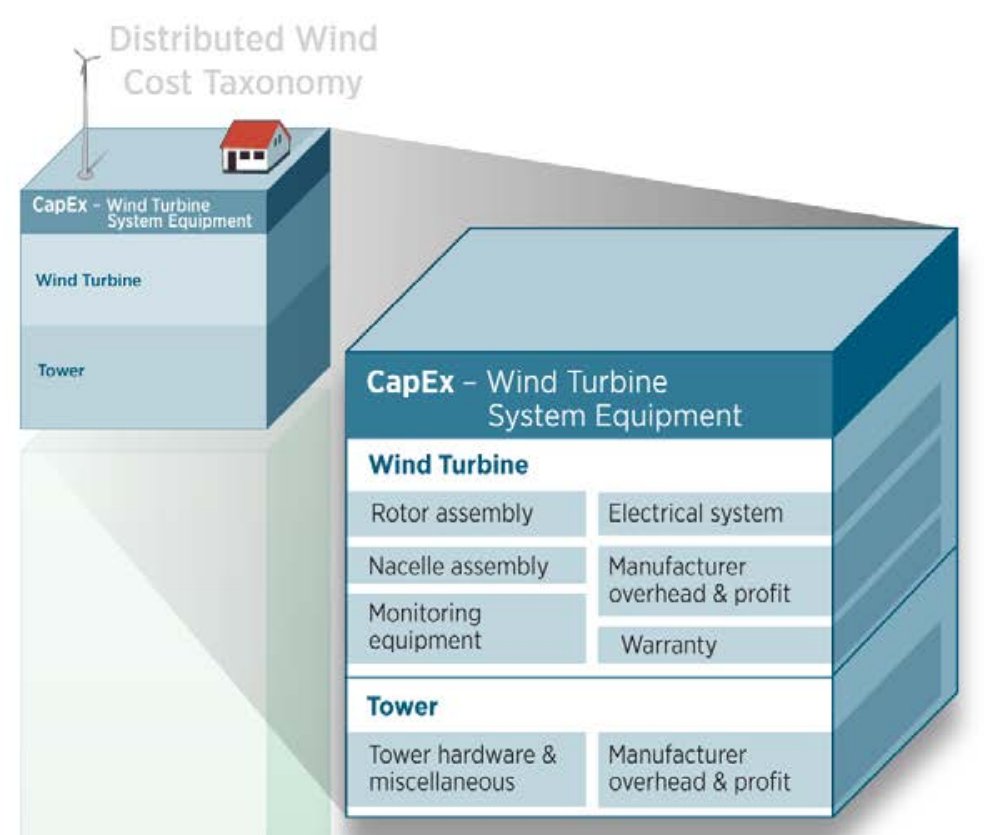

Figure 3-1. Details of wind turbine system equipment categories (CapEx)

\subsubsection{Rotor Assembly}

The rotor assembly includes all of the rotor parts, including the blades, and how they are attached to the nacelle assembly. The complexity of the rotor system varies significantly from small wind turbines that have only the blades and nose cone (the blades and nose cone are bolted to the front of the alternator) to turbines that have a rotor system that includes pitch bearings, pitch actuator, hub structure, and more. For the simple, small systems in which the blades are bolted onto the alternator, the rotor is not always a separate subassembly. In the case of larger systems, the rotor is usually assembled separately and installed onto the rest of the turbine structure.

\subsubsection{Nacelle Assembly}

The nacelle assembly is the entire wind turbine less the rotor assembly, tower, and electrical components of the electrical system (e.g., stress relief for electrical cables). It includes, at a minimum, the mainframe and cover, the drivetrain (including the generator, gearbox, and brake systems as appropriate), and the yaw system. Although the form and configuration of each of these systems vary significantly, these systems for wind turbines are universal. For example, the drivetrain can be as simple as a direct-drive alternator or it can have a gearbox, high-speed generator, and a mechanical brake. 


\subsubsection{Monitoring Equipment}

Some monitoring functions are typically built into the turbine controls. There may be additional equipment, such as a kilowatt-hour production meter, that is optional and not sold as part of the turbine control system. Additional monitoring needs may include the ability to collect and display system performance information. Even for small wind generators, some level of condition monitoring is common.

Some incentive programs require project and production data, which may include wind speed measurements and require an anemometer and a data logger. If such independent monitoring equipment is required, it is accounted for here.

\subsubsection{Electrical System}

The electrical system includes the controls, power electronics, and electrical protection equipment (including lightning protection). The controls and power electronics can be fully integrated, partly integrated, or completely separate from each other. The components can be located in the nacelle, at the base of the tower, near the grid connection point, or distributed among these locations. The generator is included as part of the nacelle assembly.

Because the controls and the power conditioning are often fully or partly integrated, they are included here. Tracking the cost of the complete electrical system will allow comparison of integrated and non-integrated systems. Today the trend is to have integrated electrical systems for most wind turbines designed to be on-grid, and most off-grid wind turbine systems have nonintegrated electrical systems.

\subsubsection{Warranty}

Warranties vary; some include parts only, some include limited labor, and some include all labor. Often both the OEM and installers have warranties to cover the complete costs of unscheduled maintenance. This category is the cost to the OEM for complying with its warranty requirements for the turbine assembly. It may involve setting aside funds to cover possible warranty expenses or to purchase insurance that covers some or all of the warranty risk. It should also contain the internal business costs of personnel to provide warranty support in addition to the cost of replacement parts and field labor expense, if that is included in the warranty.

Warranty costs are also collected under the first tier "Operations and Maintenance." These warranties typically cover labor and other costs not covered by an OEM's warranty. There may be uncovered labor costs associated with making a repair in situations where the parts are covered by a warranty, or they could cover additional parts and materials not covered by the OEM's warranty.

The warranty expense can be a large component of OEM expenses, so classifying it as a separate category within the taxonomy for turbine OEM costs is important when identifying and analyzing cost reduction opportunities.

\subsubsection{Manufacturer's Overhead and Profit}

In standard accounting practice, the primary divisions of expenses for OEMs are COGS, overhead, and profit, as described in Section 3.1.1. The "Manufacturer Overhead and Profit" second tier covers everything other than COGS (other than warranty) required to operate the 
business and would represent the difference between COGS and the market price of the turbine system, again subtracting warranty expense.

\subsubsection{Tower}

Towers are separate from the wind turbine because they are sometimes priced separately and may even be purchased from a separate manufacturer. Tower costs vary widely depending on the type and height of the tower. It is common to have multiple tower type and height options for the same model wind turbine. For small wind turbines, the cost of the tower and foundation can be the largest expense. Although they are purposefully accounted for in different parts of the taxonomy, the link between the type of tower and the tower foundation must be understood in that the type of tower influences the type of foundation needed.

Unlike the turbine system mentioned earlier, the taxonomy considers the warranty for towers as part of overhead and profit, primarily because for towers it is only a small element of overall operational costs and may be assumed under other warranty provisions. The "Tower" second-tier category is made up of the third-tier cost categories listed below, in this section.

\subsubsection{Tower Hardware and Accessories}

The tower hardware and accessories category covers the full cost of the tower structure and any accessories, such as guy wires for guyed towers, ladders for climbable towers, and rigging for tilt-up towers. This category would be included in the full COGS of the tower.

The tower anchor bolts and guy wire anchors, if used, are covered under the second-tier "Foundation" in the BOS section because they are embedded in the foundation and are needed at a different time in the installation process. They may be sourced separately or provided by the tower OEM.

\subsubsection{Manufacturer Overhead and Profit}

The "Manufacturer Overhead and Profit" second tier covers everything else (including warranty) required to operate the business and represents the difference between COGS and the market price of the tower.

\subsection{Balance of Station}

BOS within CapEx includes all activities and costs for an installed wind turbine system other than the equipment outlined in Section 3.1. Distributed wind turbine projects are deployed by installers (for small wind turbines) and developers (for large wind turbines). Their processes and methods for "getting the turbine in the ground" vary widely depending on the complexity, size, and weight of the turbine, and the work can be accomplished using different processes.

Although many of the activities covered in the BOS overlap in time, the activities have been arranged in the approximate order in which they typically take place. Figure 3-2 shows an overview of BOS activities categorized within the CapEx portion of the taxonomy. 


\section{Distributed Wind Balance of Station Overview}

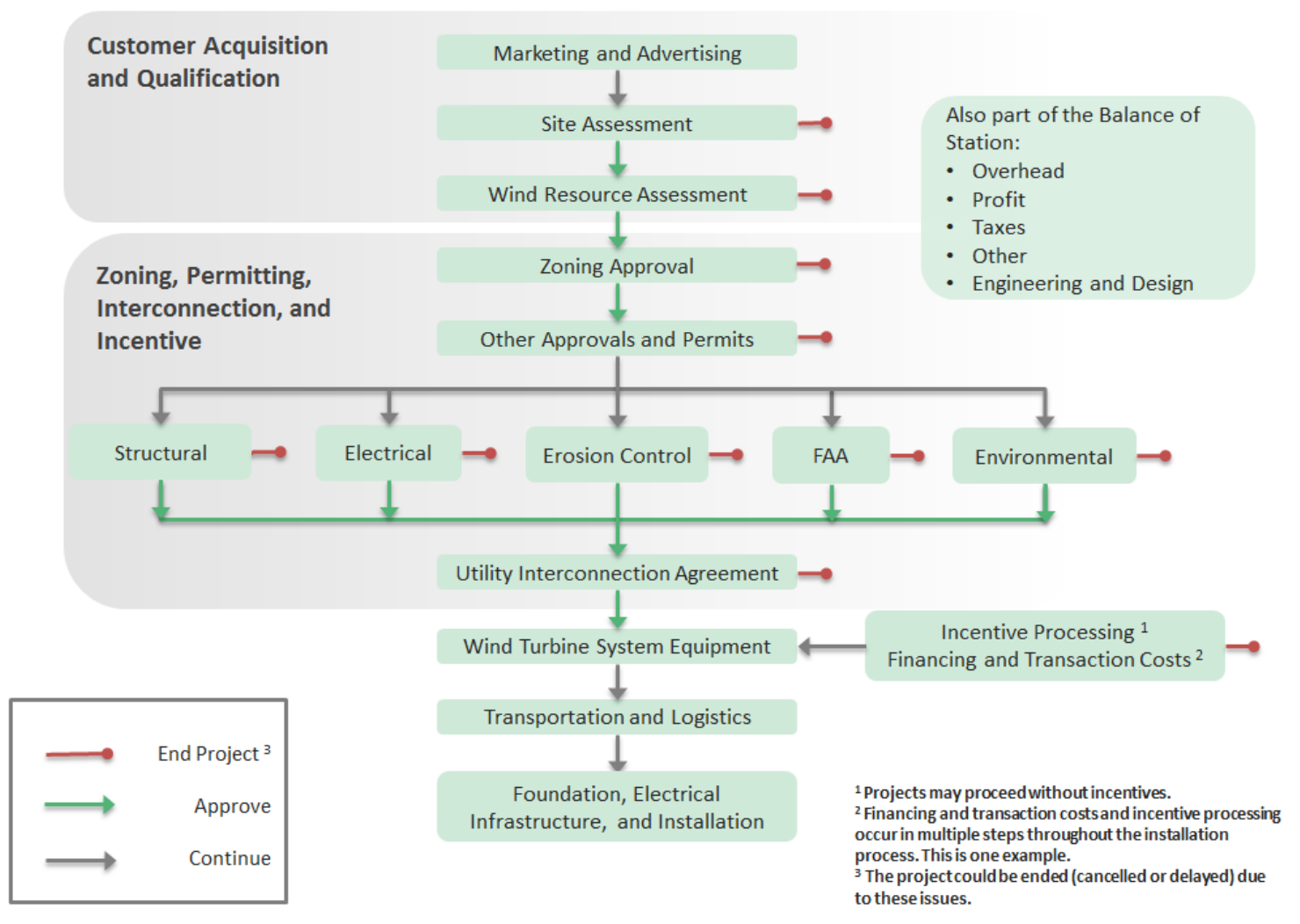

Figure 3-2. Overview of BOS activities

As Figure 3-2 shows, there are multiple and overlapping steps in the process that must be completed for the project to be sucessful. Although a project may be unsuccessful, all steps in the development process incur costs until the point of cancellation. Planned projects can be rejected in almost any part of the development process, but rejections are most common before or in the zoning approval process. (Rejection or end of project is symbolized using a red line and a dot.) The taxonomy does not address the time and costs of unsuccessful projects, but it can be used as a method to collect costs of failed or delayed projects, either explicitly or as part of a wider assessment of multiple projects. The green lines in Figure 3-2 show approval of the step in the process. Project location will influence how many of these approvals are needed. The grey line shows the project proceeding to the next step - no approvals necessary.

Based on preliminary data collection, some installers estimated only

1 in 10 efforts to install a wind turbine results in a successful project, so they typically develop preliminary screening processes to minimize effort on projects with a low probability of success. 
Figure 3-3 provides a detailed overview of the first-tier BOS (CapEx) part of the taxonomy, and it shows the divisions in the second (bold text) and third (plain text in green bricks) tiers.

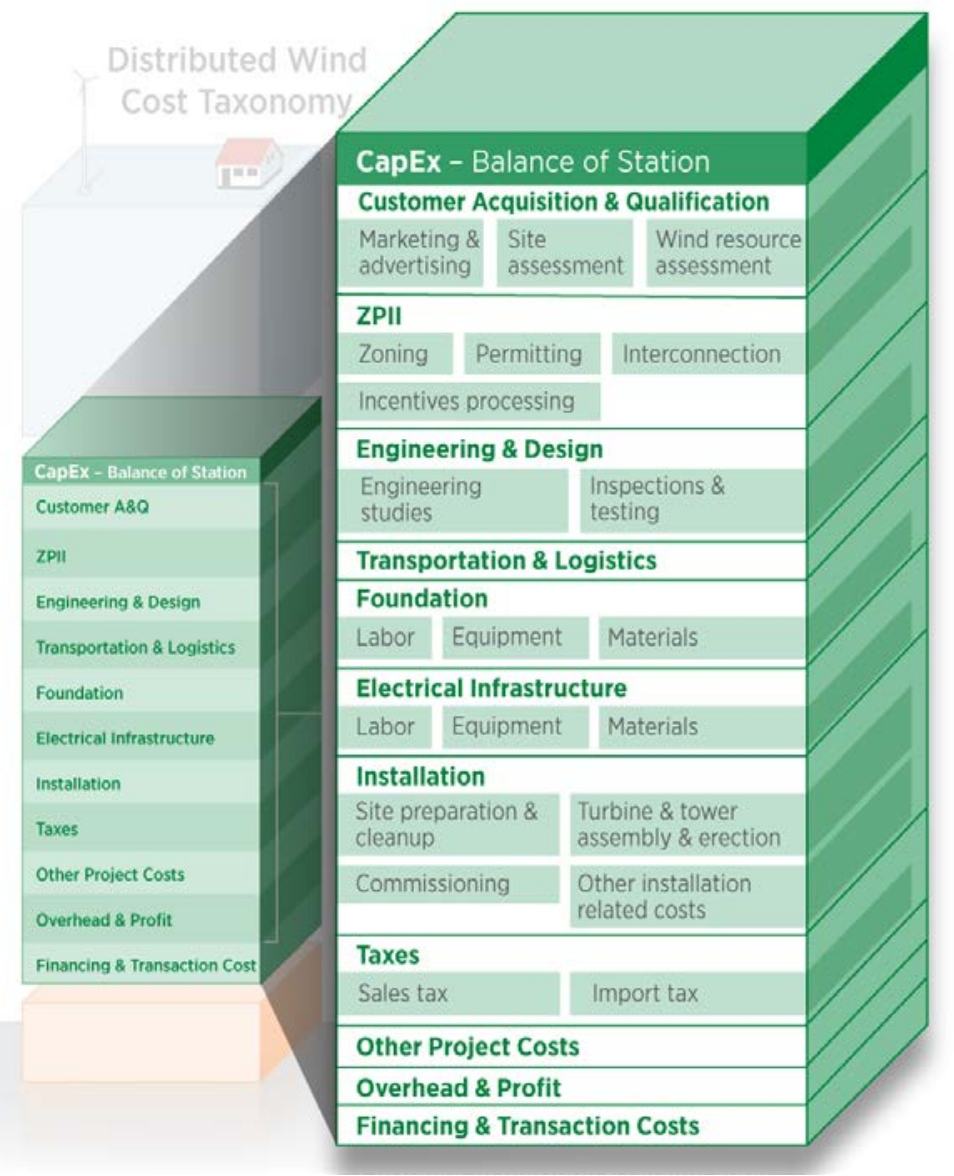

Figure 3-3. Details of BOS (CapEx) cost categories

The distributed wind industry uses a large range of turbine sizes, resulting in significant differences in equipment requirements, engineering studies, access issues, site preparation protocols, and other factors. The BOS tier of the taxonomy was developed to account for this wide variety of deployments and supports the collection and analysis of quantitative data.

Although the third-tier category is the lowest level provided directly in the taxonomy, it is likely that different manufacturers or analysis projects may further categorize expenses within each tier. For example, "Site Preparation and Clean-Up" could be further divided into Labor, Equipment, and Materials as fourth-tier categories.

\subsubsection{Customer Acquisition and Qualification}

Identifying a potential project and customer and then determining if that project is viable are the first steps in the turbine installation process. Following identification of new turbine customers, there are several steps to determining project viability, such as an assessment of the site and the wind resource. The taxonomy divides the process of determining whether a project is viable into three categories: marketing and advertising, site assessment, and wind resource assessment. 
General accounting practices could include customer acquisition within overhead. Because of its unique challenges for distributed wind (e.g., wind resource assessment), the category of "Customer Acquisition and Qualification" has been included as a second-tier category in the taxonomy.

\subsubsection{Marketing and Advertising}

This category covers all of the expenses for marketing and advertising associated with acquiring a potential customer. This could include many elements, from visiting potential customers, staffing booths at events, and conducting other direct outreach, as well as pursuing indirect outreach such as hosting websites, conducting mass mailings, or advertising in local periodicals. For larger companies, these activities can include maintaining a sales staff. These efforts are typically not associated with specific projects but are a more general cost of business and are sometimes allocated as part of overhead costs that may be spread across a number of projects.

\subsubsection{Site Assessment}

Costs associated with site assessment will vary depending on the project size and turbines to be used. For smaller projects, this activity may be as simple as a site visit to assess any potential access, logistics, or environmental problems. A general understanding of the wind resource availability can also be determined on-site. For larger projects, more detailed site assessment work will be required, such as initial geotechnical analysis and further environmental screening. In some cases, specific engineering requirements may be required for permits, regardless of the actual engineering need, in which case these costs should be accounted for as part of permitting.

\subsubsection{Wind Resource Assessment}

Costs to assess the wind resource at a potential project location are included in this category. Costs can vary extensively by project size and financing structures. Small projects not requiring financing may need only a limited resource assessment whereas larger, bank-financed projects may require active on-site measurements to improve power production estimate reliability. Costs can include site-specific measurement equipment, such as a tower, as well as labor and staff time to process these resulting data. As the distributed wind turbine project costs increase, the need for accuracy in the wind resource projections increases, resulting in higher costs for larger turbine projects.

\subsubsection{Zoning, Permitting, Interconnection, and Incentive Processing}

ZPII activities are completed before the foundation, electrical infrastructure, and installation of a distributed wind turbine can begin. This second-tier category includes permit fees and labor costs associated with obtaining the appropriate zoning approval, permits, and interconnection agreements and processing the required forms for local, state, and federal incentives. Projects can be rejected at any point during these steps if a permit application is not approved. It should be noted that especially for residential-size systems, some installers do not charge for their time to pursue the ZPII approvals. The taxonomy has room to break out both time (processing and calendar time) and costs (labor and fees) that are required for pursuing regulatory and utility approvals. 


\subsubsection{Zoning}

Zoning ordinances define the rules or regulations that local governments apply to buildings or structures on private land. Although some communities have zoning ordinances that allow the development of distributed wind projects, wind turbine systems typically fall outside standard community zoning ordinances. This means that one of the first costs to develop distributed wind projects is to seek approval for a variance in local zoning ordinances.

This category covers all costs associated with applying, developing the appropriate documentation, and working through the zoning variance process. Costs can vary greatly based on the project size, location, specific zoning ordinance in question, and the type of variance approval process required by the local jurisdiction. In most cases, the costs typically include a small filing fee and then labor to develop the required material to seek the variance. Some jurisdictions have zoning ordinances that specifically cover distributed wind, which greatly simplifies this process for projects that conform to the regulations. ${ }^{3}$

Obtaining a variance will usually require neighbor notification and potentially a public hearing before the zoning board. In some areas, the applicant pays for the hearing, which may cost a few hundred to a few thousand dollars. For larger projects, costs associated with obtaining variances can be quite high if developers are forced to include site tours, visits to other wind facilities, extensive analysis of project impacts, or employing experts to testify about impacts and risks.

Zoning regulations are required across the nation. However, there are more than 20,000 local jurisdictions that govern zoning in the United States, each with their own rules and procedures, which vary greatly (Green 2008). Each project, even in the same jurisdiction, requires approval of the local decision-makers, which means that limited economies of scale can be achieved.

Additionally, a jurisdiction may have different rules covering development with different parts of a community, such as residential, commercial, or industrial zones. Policies covering larger distributed wind projects that are developed for an industrial customer on land that is already zoned for industrial use are likely to be more accommodating than policies for projects being placed in residential zoning areas. Industrial clients may also manage their own zoning processes, which would reduce these costs for the project developer.

As described previously, considering zoning costs, labor, and calendar time to complete zoning variance approvals separately will allow a better understanding of the regional and project size variation and the impact of zoning on the U.S. distributed wind market.

\subsubsection{Permits}

After receiving the more general zoning approval, other permits must be obtained. Typical permits include, but are not limited to, structural; electrical; erosion control; Federal Aviation Administration determination (for turbines 200 feet above ground level or taller, or near airports); local, state, or federal environmental impact permits; and historical protection. Some permits may require engineering assessments, such as a review of the tower structure or

\footnotetext{
${ }^{3}$ Examples of wind energy ordinances are provided in this database: http://apps2.eere.energy.gov/wind/windexchange/policy/ordinances.asp
} 
foundation design, and a signature from a licensed professional engineer. Cost for engineering support for permit approval is tabulated as part of the overall permit costs. Permits always entail fees, but the fee varies widely by type and jurisdiction. Examples include a set fee (such as $\$ 85$ for an electrical branch breaker addition) or a percent of the value of the project (such as $4 \%$ of the value of the foundation).

\subsubsection{Interconnection}

Connection to the utility grid requires an approved interconnection agreement, which typically requires a site inspection and validation of the wind turbine system controls and operation. For residential-size systems, this is usually a simple standard contract provided by the local utility. Larger systems may require an engineering analysis of the distribution feeder and the upgrades that may be required to allow successful interconnection without impacting power quality for other customers on that feeder. Interconnection and engineering studies can be expensive and may be performed by the utility or a consulting firm (typically paid for by the project owner).

\subsubsection{Incentive Processing}

Many projects have the ability to take advantage of local, state, federal, and/or utility-based incentives. These incentives typically require application paperwork; some incentives, such as the U.S. Department of Agriculture's Rural Energy for America Program grant, may require an application that is competitively selected. The installer often prepares these applications for the customer. Incentive applications or awards may have costs, such as an application fee, a requirement for data monitoring equipment or special meter, or liability insurance. There may be conditions for the receipt of an incentive, such as a notarized financial audit or demonstration of energy production consistent with projections. An example of the costs for incentive processing comes from the installer of a residential-size wind turbine project in New York State. The installer logged 40 hours completing the state environmental filing to qualify the project for local incentives.

\subsubsection{Engineering and Design}

The engineering and design work on a project is often performed over an extended time period, from the beginning of the customer acquisition to the beginning of installation. Some engineering work is completed early in the process to allow initial project assessment whereas other work is required later in response to zoning or permitting requirements. In these cases, any engineering or design costs should be assigned to those respective categories. Other engineering or system design needs should be accounted for in the "Engineering and Design" categories in the following sections.

\subsubsection{Engineering Studies}

This category covers engineering studies that are not required for customer permit approvals. These studies can include basic design for project cost estimating, structural analysis, and electrical design if the project differs from standard electrical interconnections. Larger projects will require a more in-depth engineering analysis whereas many small wind OEMs provide generic engineering studies that can be applied to multiple projects. Engineering costs related to permits are captured within this taxonomy as part of the permit costs. 


\subsubsection{Inspections and Testing}

This category was implemented to account for any additional testing or inspection expenses that are not covered under other taxonomy sections. For example, if minimum compression strength is specified for the concrete, there may also be a requirement to test the concrete after curing. Costs for these types of activities would be captured in this category.

\subsubsection{Transportation and Logistics}

All materials, including the wind turbine and tower, must be transported to the site. Sometimes intermediate warehousing of equipment prior to shipping to the customer location is required. Costs in this second-tier category include standard shipping based on truck, rail, or other shipping needs; warehousing; local storage needs; specialty trailers; or additional costs associated with transporting oversized equipment. Large turbine projects also require logistics and process plans for activities, such as receiving turbine and tower hardware, loading and unloading turbine components, organizing component storage, identifying assembly locations, and orchestrating turbine construction timing. This more focused figure (Figure 3-4) shows the BOS (CapEx) from "Transportation and Logistics" through "Taxes."

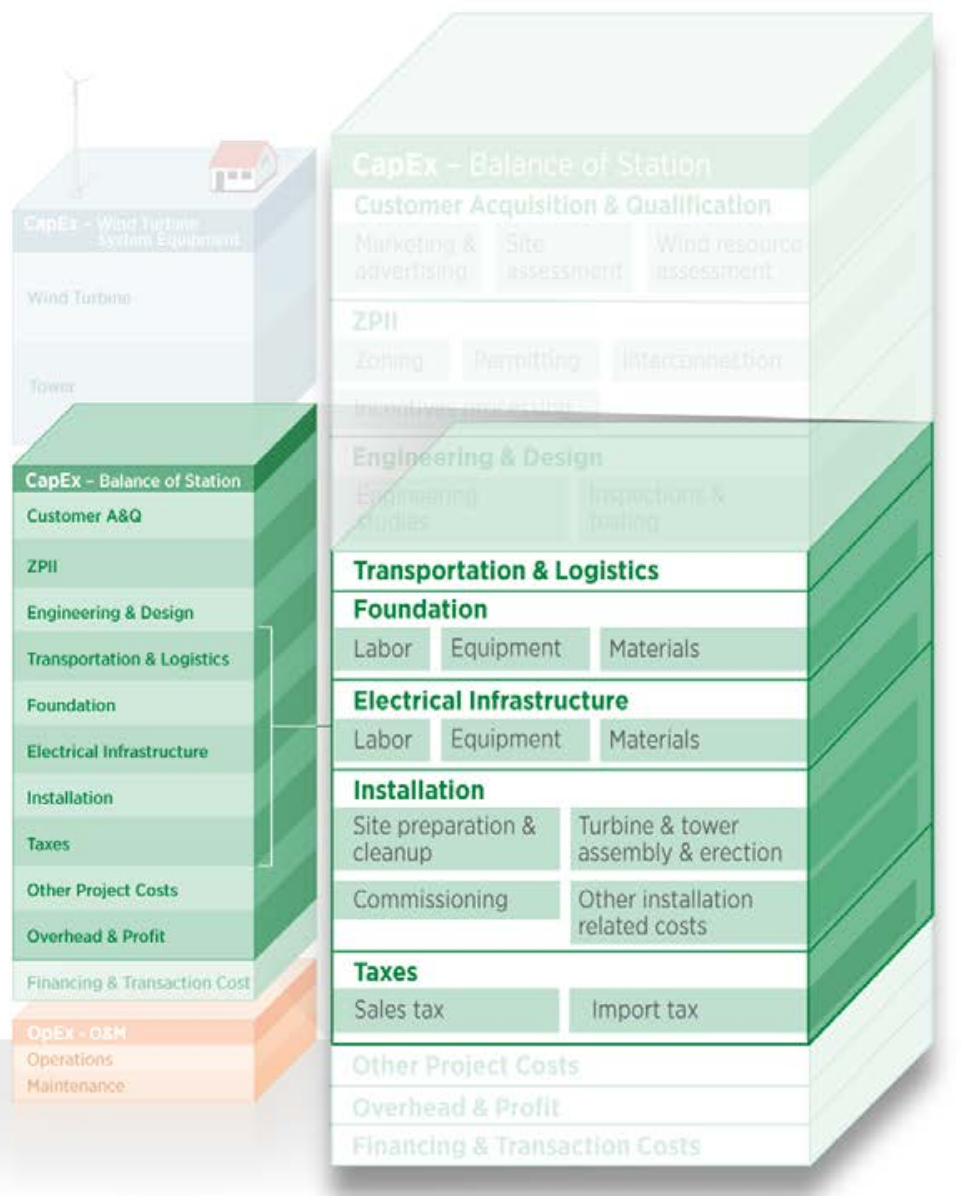

Figure 3-4. Break-out of the BOS (CapEx) categories from "Transportation and Logistics" to "Taxes" 


\subsubsection{Foundation}

The excavation, rebar assembly, and concrete pour are the minimum costs for a typical foundation installation and will depend on the foundation design and soil properties. Costs may also be incurred in renting concrete forms, although in some cases the hole can be sized to act as the form. Each element of the foundation development will require equipment and labor. Foundations also include material costs, such as rebar and concrete. Usually an inspection is conducted before the concrete pour; this cost may be included in permit costs but if not, it is included in the "Engineering and Design" second-tier item. The labor, equipment, and material costs are in the next level of detail in the taxonomy for foundations.

For small wind turbine projects for which the installer may undertake all aspects of the installation, the logistics of mobilizing a crew for the foundation, demobilizing and waiting for the foundation to cure, and then mobilizing again for turbine installation add to the installation cost. Alternatively, the foundation work may be completed by a specialty contractor at an invoice price that does not break out material, equipment, and labor costs.

\subsubsection{Electrical Infrastructure}

Building the electrical infrastructure includes tasks such as wiring the turbine through the tower to controls and installing the wire run from the base of the tower to the utility interconnection or on-site power distribution system. The wire run is usually underground, so it would include trenching and backfill. On larger distributed wind projects, electrical interconnection may include a transformer and medium-voltage interconnection. The labor, equipment, and material costs are the next level of detail in the taxonomy under "Electrical Infrastructure" and may be collectible if the electrical work is done by the installer or developer or itemized in the electrical infrastructure subcontract.

\subsubsection{Installation}

The taxonomy divides installation into four categories relating to different parts of the installation process. Site preparation is typically the first step in the turbine installation process followed by the assembly, erection of the turbine, and then commissioning. A fourth general category is included to account for any additional costs. In using the taxonomy, it may be useful to further divide each installation activity into labor, equipment, and materials costs.

\subsubsection{Site Preparation and Cleanup}

The site preparation and cleanup category covers all costs associated with the development and restoration of the area around a turbine installation. For larger turbine projects, modifications to the access roads may be required to allow delivery of long or heavy components. It may be necessary to level installation areas, create temporary roads, or develop laydown pads to facilitate turbine installation. This level area may need to be created for the construction equipment, the turbine equipment waiting to be assembled, and the crane. At the end of the project, all temporary improvements must be removed, and the site must be restored. Projects with smaller turbines typically do not require modifications to access roads, creation of crane pads, or temporary buildings. 


\subsubsection{Turbine and Tower Assembly and Erection}

A number of costs are included in the category for erection of the turbine and tower. For all but the smallest installation projects that could utilize a tilt-up tower, a crane is required to complete the assembly and erection. Crane costs typically include hourly, daily, or weekly rates; crew labor and per diem; and mobilization and demobilization costs. For small wind turbines that only require smaller, mobile cranes, the mobilization charge is typically the hours that the crane must travel to arrive at the site. For large wind turbines, the required crane must be assembled on-site, requiring a dozen or more trucks to deliver the crane and a mobile crane to assemble the large crane.

Other costs that may be required to support the turbine erection could include additional specialized labor and specialty equipment or tools. Additional costs may be incurred due to delays in the turbine erection caused by weather events or high wind speeds.

\subsubsection{Commissioning}

Commissioning of the wind turbine includes inspection of electrical and mechanical work followed by progressive functional tests, as detailed in the turbine OEM's installation manual. The installation crew usually commissions small wind turbines. For larger projects, the manufacturer may send a special crew to complete the commissioning. In addition to OEMspecified work, local regulations may require additional tests or inspections by the authorities having jurisdiction, a certified third party, and/or the utility. The utility interconnection inspection process, which is included in the ZPII "Interconnection" third tier, typically requires a site visit to validate that the turbine installation is consistent with the interconnection agreement, has been approved by the authorities having jurisdiction, and trips off-line on loss of utility power.

\subsubsection{Other Installation-Related Costs}

"Other Installation-Related Costs" is a general category covering any additional costs that do not fit in the categories discussed earlier, including construction management, installer warranty, additional subcontracts, materials, labor, and equipment.

\subsubsection{Taxes}

Many states or local jurisdictions have sales or other taxes that can be a significant part of the total installed cost of a system. Any other local tax (other than property) would also be included here. Property tax is not part of the installed cost of a project and is covered under operation and maintenance (Section 3.3). This second-tier category also includes import taxes that may be incurred.

\subsubsection{Other Project Costs}

This is a general category for project costs that are not covered in other categories. For example, large distributed wind projects will incur general project management costs that are not accounted for elsewhere and are typical for projects implemented by a developer. Project management is needed to manage many specialty contractors that may be part of developer services or may be contracted out. Large wind projects may also include an office trailer, sanitation facility, storage for tools and supplies, and a security fence. 
Decommissioning costs can be captured here, in a fourth-tier category, if a decommissioning bond is required. Projects with smaller turbines typically will not require a decommissioning bond. Projects with larger turbines may require decommissioning bonds, which could be captured here or under "Operations and Maintenance," if the requirement is for an annual payment to a decommissioning fund.

\subsubsection{Overhead and Profit}

The installer or developer will have overhead expenses that are not directly billable to a specific project. The difference between their costs for the project and the installed wind turbine system price to the customer is the overhead and profit, which must cover all common business expenses such as office space, administrative labor, corporate management expenses, and business operations.

\subsubsection{Financing and Transaction Costs}

Financing depends on the project's ownership and business model but would include costs associated with not only the servicing of project debt but also any transactional costs, investor due diligence, and investment insurance. Land owners and retail electricity consumers who plan to own a small wind turbine project usually pay in cash or secure a simple bank loan. Larger projects require various funding sources, which will require additional transactional expenses. Obtaining institutional financing for third-party-owned projects often precedes customer acquisition because funding is raised to finance a group of projects.

\subsection{Operations and Maintenance}

The operations and maintenance top tier divides these costs into two second-tier categories: "Operations" and "Maintenance." Figure 3-5 shows the cost categories within "Operations and Maintenance."

\subsubsection{Operations}

Although operations are a significant expense for utility-scale, large wind turbine projects, operation expenses for smaller distributed wind projects are often not significant and may not even be tracked. Examples of such costs could include land lease payments (typical for utilityscale wind plants but not usually applicable for behind-the-meter distributed wind projects), remote monitoring, various operations contracts or retainers, insurance, and property taxes.

If a decommissioning fund is required, the costs of the annual payments can be collected as a fourth tier category under "Operations." Decommissioning funds are not typically required of projects with smaller turbines. Decommissioning bonds are a one-time payment and are included in a fourth-tier category under BOS "Other Project Costs." 


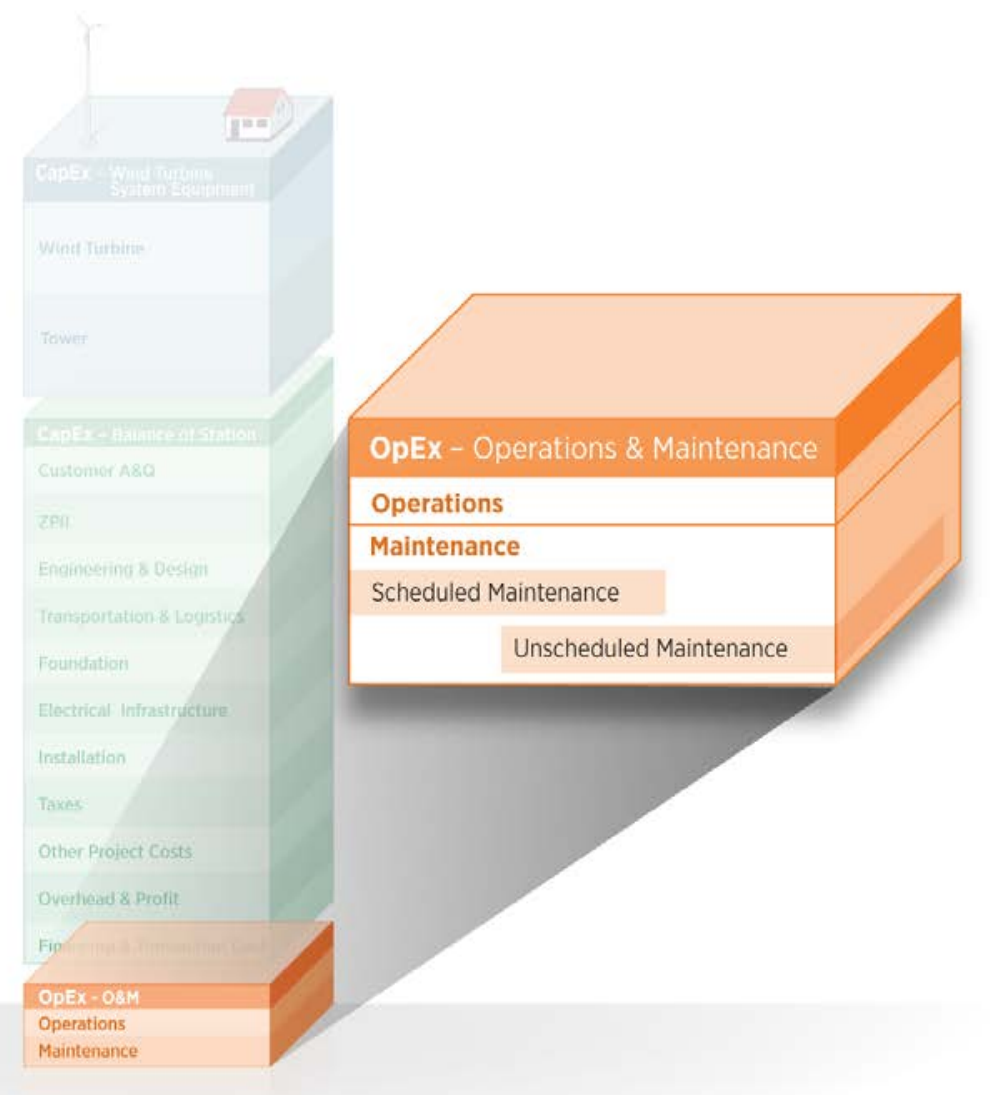

Figure 3-5. Details of Operations and Maintenance cost categories

\subsubsection{Maintenance}

This second-tier category covers scheduled and unscheduled maintenance costs. Maintenance expenses may be the responsibility of the end user, the turbine owner, or the turbine OEM depending on the ownership structure, warranty, and warranty status.

\subsubsection{Scheduled Maintenance}

Scheduled maintenance is expected and performed periodically to keep the turbine operating reliably. It includes oil and filter changes, bolt torque checks, brake pad wear checks and replacements, greasing lubricated parts, and visual inspections. Depending on the size and complexity of the wind turbine, these scheduled maintenance activities are conducted every 6 months to 2 years. Some small turbine manufacturers are pushing scheduled maintenance out to 3 years, and the smallest (less than $5 \mathrm{~kW}$ ) have no scheduled maintenance.

Turbines without scheduled maintenance often have a list of preventive maintenance items that are performed any time a repair (unscheduled maintenance) operation happens. The larger turbines have more complex systems, such as hydraulic pitch control and active yaw, that increase scheduled maintenance costs. These systems may require more frequent scheduled maintenance than a simpler small turbine that is direct drive (no gearbox), free yaw, and stall- 
regulated (no pitch system). The mobilization of people, equipment, tools, and needed materials to the site would also be included in maintenance costs.

Scheduled maintenance can be covered by a long-term service contract. For large turbines, a service contract with an approved organization is often a requirement during any manufacturerprovided warranty period.

\subsubsection{Unscheduled Maintenance}

Unscheduled maintenance is initiated by a failure. Unscheduled maintenance includes the full costs of any maintenance that is not scheduled maintenance. Costs assigned to this category mirror those identified for scheduled maintenance.

\section{Conclusions}

The Distributed Wind Cost Taxonomy was developed to cover the full range of installed wind turbine system costs for all project sizes, interconnected to different utility service providers or in off-grid applications, regardless of location. It captures the costs of the wind turbine system, the costs to install and operate the turbine at a specific site, and the costs associated with the installer's or developer's business. It has been vetted through meetings with industry leaders and validated by data collection and follow-up interviews with installers and developers.

The taxonomy was developed to provide value to the industry and its different stakeholders by understanding the details of wind turbine system costs. By using the same taxonomy across the distributed wind market, different project costs will be comparable and can be used to indicate cost trends and progress against industry benchmarks.

Developing the taxonomy presented challenges, and some cost data in the taxonomy will be difficult to gather. Challenges encountered during the taxonomy development are listed below.

- Preliminary data collection using the taxonomy identified some project costs that were unique to just one or two projects (e.g., cyber security costs). Because it did not make sense to include distinct taxonomy categories for unique costs, the inclusion of "other" categories within the taxonomy is used to address these cost items so they can still be tracked.

- Some costs in the taxonomy are confidential and will be more difficult to acquire and classify because they cover the installer's or developer's business overhead and profit. These costs are still relevant to a sustainable business and understanding the business structure. A modeling approach may be needed to inform business overhead and profit values.

- Financing details of the projects are difficult to gather and break out. This is particularly true for small wind turbine projects that are funded directly by the customer with little involvement by the installer. For the midsize and larger turbine projects as illustrated in Figure 2-2, financing may be part of the package provided by the developer (particularly for those projects selling electricity, not turbine ownership). Third-party ownership, such as leasing of wind turbines, is a relatively new concept and follows the successful leasing 
models used for PV projects. It could be difficult to fully understand the costs and details at this early stage of the leasing model.

- As the method of selling wind turbines shifts and expands (e.g., to third-party ownership structures), the flexibility of the taxonomy will be tested.

- Subcontracted services such as foundation design and build and electrical infrastructure design and build may be difficult to divide into labor, equipment, and material costs (although some of these preliminary data do have labor, equipment, and material costs divided for foundation and electrical infrastructure). These data can inform a model to disaggregate bundled, subcontracted services.

- The taxonomy is focused on the turbine system and does not include other important factors that may have an impact of total system costs, such as project location, tower height, turbine type and weight, or other special considerations. For analysis purposes, full utilization of project cost data requires the collection of business and project metadata (e.g., location of project, type of turbine) in addition to the cost descriptions covered in this taxonomy.

It is worth noting that the taxonomy requires detailed cost input and breakdown to fully assess cost variations and cost reduction opportunities. For example, the taxonomy could be used to record the costs of projects that were not ultimately installed. This might be useful in determining the investment a company makes during the different steps of the project development process. Alternatively, if the interest is to better understand the cost of specific projects, then only those projects that were completed would be of interest.

The Distributed Wind Cost Taxonomy is designed to serve the industry over the long term as a tool that can:

- Elucidate wind turbine system costs and business models, such as third-party ownership

- Enable different stakeholders to understand the breakdown of project costs

- Allow for comparison of different ZPII processes used by jurisdictional authorities and utility service providers

- Inform cost reduction approaches and scenarios

- Provide a basis for benchmarking and tracking cost reduction progress of distributed wind turbine system costs over time.

Based on preliminary data, the Distributed Wind Cost Taxonomy has proven to be flexible and all-encompassing enough to cover, categorize, and compare diverse, distributed wind turbine project costs. 


\section{References}

American Wind Energy Association. 2017. Wind Energy Facts at a Glance.

http://www.awea.org/Resources/Content.aspx?ItemNumber=5059\&navItemNumber=742.

Accessed March 10, 2017.

Barbose, G., N. Darghouth, D. Millstein, S. Cates, N. DiSanti, and R. Widiss. 2015. Tracking the Sun IX: The Installed Price of Residential and Non-Residential Photovoltaic Systems in the United States. Berkeley, CA: Lawrence Berkeley National Laboratory. Report No. LBNL1006036. https://emp.lbl.gov/sites/all/files/lbnl-188238_1.pdf

Bloomberg New Energy Finance. 2017. Sustainable Energy in America Factbook. Business Council for Sustainable Energy. www.bcse.org

Chung, Donald, Carolyn Davidson, Ran Fu, Kristen Ardani, and Robert Margolis. 2015. U.S. Photovoltaic Prices and Cost Breakdowns: Q1 2015 Benchmarks for Residential, Commercial, and Utility-Scale Systems. Golden, CO: National Renewable Energy Laboratory. Report No. NREL/TP-6A20-64746. http://www.nrel.gov/docs/fy15osti/64746.pdf

Friedman, B., K. Ardani, D. Feldman, R. Citron, R. Margolis, and J. Zuboy. 2013. Benchmarking Non-Hardware Balance-of-System (Soft) Costs for U.S. Photovoltaic Systems, Using a Bottomup Approach and Installer Survey - Second Edition. Golden, CO: National Renewable Energy Laboratory. Report No. NREL/TP-6A20-60412. http://www.nrel.gov/docs/fy14osti/60412.pdf

Green, H. James. 2008. Overview: Zoning for Small Wind Turbine. ASES Small Wind Division webinar. Golden, CO: National Renewable Energy Laboratory.

http://apps2.eere.energy.gov/wind/windexchange/pdfs/workshops/2008/sw_zoning_overview.pdf

Labastida, R. R., Gauntlett, D., 2017. Navigant Research. Next-Generation Solar PV: High

Efficiency Solar PV Modules and Module-Level Power Electronics: Global Market Analysis and Forecasts. Published 3Q 2016. https://www.navigantresearch.com/research/next-generation$\underline{\text { solar-pv }}$

Lantz, Eric, Benjamin Sigrin, Michael Gleason, Robert Preus, and Ian Baring-Gould. 2016. Assessing the Future of Distributed Wind: Opportunities for Behind-the-Meter Projects. Golden, CO: National Renewable Energy Laboratory. Report No. NREL/TP-5000-67337. http://www.nrel.gov/docs/fy17osti/67337.pdf

Moné, C., A. Smith, B. Maples, and M. Hand. 2015. 2013 Cost of Wind Energy Review. Golden, CO: National Renewable Energy Laboratory. Report No. NREL/TP-5000-63267.

http://www.nrel.gov/docs/fy15osti/63267.pdf

Orrell A. and N. Foster. 2016. 2015 Distributed Wind Market Report. Richland, Washington: Pacific Northwest National Laboratory. Report No. PNNL-25636. U.S. Department of Energy Office of Energy Efficiency and Renewable Energy. https://energy.gov/sites/prod/files/2016/08/f33/2015-Distributed-Wind-Market-Report$081620160 . \mathrm{pdf}$ 
U.S. Department of the Treasury. 2016. "Overview and Status Update of the $§ 1603$ Program." https://www.treasury.gov/initiatives/recovery/Documents/STATUS\%20OVERVIEW.pdf

United States National Commission on Urban Problems. 1969. Building the American City : Report of the National Commission on Urban Problems to the Congress and to the President of the United States, Publisher Washington, D.C.: For sale by the Supt. of Docs., U.S. Govt. Printing Office. https://archive.org/details/buildingamerican00unit_0 